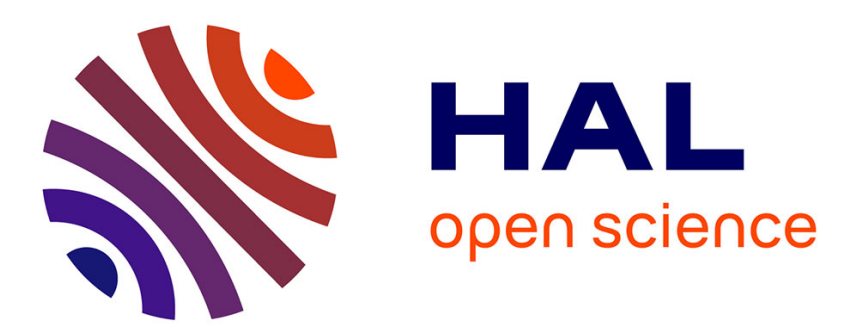

\title{
High-throughput Microscopic Analysis of Salmonella Invasion of Host Cells
}

\author{
Jakub Voznica, Jost Enninga, Virginie Stévenin
}

\section{To cite this version:}

Jakub Voznica, Jost Enninga, Virginie Stévenin. High-throughput Microscopic Analysis of Salmonella Invasion of Host Cells. Bio-protocol , 2018, 8 (18), 10.21769/BioProtoc.3017 . pasteur-01899390

\section{HAL Id: pasteur-01899390}

\section{https://hal-pasteur.archives-ouvertes.fr/pasteur-01899390}

Submitted on 19 Oct 2018

HAL is a multi-disciplinary open access archive for the deposit and dissemination of scientific research documents, whether they are published or not. The documents may come from teaching and research institutions in France or abroad, or from public or private research centers.
L'archive ouverte pluridisciplinaire HAL, est destinée au dépôt et à la diffusion de documents scientifiques de niveau recherche, publiés ou non, émanant des établissements d'enseignement et de recherche français ou étrangers, des laboratoires publics ou privés. 


\title{
High-throughput Microscopic Analysis of Salmonella Invasion of Host Cells
}

Jakub Voznica $^{1,2}$, Jost Enninga ${ }^{1}$ and Virginie Stévenin ${ }^{1, *}$

\author{
${ }^{1}$ Dynamics of Host-Pathogen Interactions Unit, Institut Pasteur, Paris, France; ${ }^{2}$ Department of Biology, \\ Ecole Normale Supérieure Paris-Saclay, Cachan, France \\ *For correspondence: virginie.stevenin@ens-cachan.fr
}

\begin{abstract}
[Abstract] Salmonella is a Gram-negative bacterium causing a gastro-enteric disease called salmonellosis. During the first phase of infection, Salmonella uses its flagella to swim near the surface of the epithelial cells and to target specific site of infection. In order to study the selection criteria that determine which host cells are targeted by the pathogen, and to analyze the relation between infecting Salmonella (i.e., cooperation or competition), we have established a high-throughput microscopic assay of HeLa cells sequentially infected with fluorescent bacteria. Using an automated pipeline of image analysis, we quantitatively characterized a multitude of parameters of infected and non-infected cells. Based on this, we established a predictive model that allowed us to identify those parameters involved in host cell vulnerability towards infection. We revealed that host cell vulnerability has two origins: a pathogen-induced cellular vulnerability emerging from Salmonella uptake and persisting at later stages of the infection process; and a host cell-inherent vulnerability linked with cell inherent attributes, such as local cell crowding, and cholesterol content. Our method forecasts the probability of Salmonella infection within monolayers of epithelial cells based on morphological or molecular host cell parameters. Here, we provide a detailed description of the workflow including the computer-based analysis pipeline. Our method has the potential to be applied to study other combinations of host-pathogen interactions.
\end{abstract}

Keywords: Salmonella enterica serovar Typhimurium, Epithelial cell infection, Host cell heterogeneity, High-throughput microscopy, Image segmentation, Mathematical modeling

[Background] Salmonella enterica serovar Typhimurium infects its host via ingestion of contaminated food or water, causing salmonellosis. Once the bacterium reaches the distal ileum of the gut, they can invade a broad range of host cells, including the intestinal epithelial cells (Watson and Holden, 2010). During the first phase of host cell invasion, Salmonella chooses its targets, using its flagellum to swim and scan the surface of the epithelium (Misselwitz et al., 2012). After several stops on the surface of the cells, the bacterium eventually chooses a site where it docks (Misselwitz et al., 2011; Vonaesch et al., 2013) and triggers its uptake via the Type 3 Secretion System (T3SS) (Haraga et al., 2008; LaRock et al., 2015). The injection of bacterial effectors directly into the cytosol of the targeted cells leads to a strong remodeling of the actin cytoskeleton and the formation of membrane ruffles that engulf the pathogen (Haraga et al., 2008; LaRock et al., 2015). Within the infected cells, Salmonella remains either within a mature endomembrane compartment, the Salmonella-containing vacuole (SCV); or it reaches the cytosol by SCV membrane rupture to replicate at distinct paces within the different intracellular niches (Knodler, 2015; Fredlund et al., 2018). 
Eukaryotic cell monocultures display an intrinsic cellular heterogeneity. Indeed, after seeding, cells have different characteristics with regards to their morphology and the local microenvironment, which correlates with differences of the transcriptome, proteome, and lipidome (Snijder et al., 2009; Frechin et al., 2015; Liberali et al., 2015). The selection criteria that determine which host cells are targeted by Salmonella for invasion are poorly understood. Previously, Misselwitz and colleagues proposed that Salmonella preferentially targets the topological obstacles it encountered while swimming near the cell monolayer, such as ruffles or mitotic cells (Misselwitz et al., 2012; Lorkowski et al., 2014). In contrast, Santos and colleagues suggested that cholesterol accumulation during cell metaphase is responsible for mitotic cell targeting (Santos et al., 2013). In a recent study, we investigated at the single-cell level the criteria exploited by Salmonella to select the cell to infect in a naturally heterogeneous monolayer of cells (Voznica et al., 2018).

In order to link the features of each cell with its probability to be infected, we have established a protocol of double infection of HeLa cells with fluorescent bacteria. We imaged the cells with highthroughput microscopy combined with automatic image analysis to obtain the individual features of hundreds of thousands of cells. We observed the distribution of those features in infected and noninfected cells and used a mathematical model to resolve the importance of different cellular parameters in deciphering Salmonella targeting.

This protocol provides a new tool to analyze pathogen targeting of cell features in a non-invasive manner and at the single-cell level. This opens a new path to decipher the cellular and bacterial factors involved in host cell vulnerability to infection.

\section{Materials and Reagents}

A. Cell culture

1. Falcon ${ }^{\circledR} 15 \mathrm{ml}$ Polystyrene Centrifuge Tubes, Conical Bottom, with Dome Seal Screw Cap, Sterile (Corning, catalog number: 352095)

2. Counting chamber (KOVA ${ }^{\circledR}$ Glasstic Slide 10 with Grids) (Kova International, catalog number: 87144)

3. 96-well cell culture microplate with clear flat bottom (Greiner Bio One International, catalog number: 655090)

4. $75 \mathrm{~cm}^{2}$ tissue culture flasks with tilting neck and filter caps (TPP Techno Plastic Products, catalog number: 009076)

5. Human epithelial HeLa cells (ATCC, catalog number: CCL-2)

6. Dulbecco's Modified Eagle's Medium (DMEM) 1x, High Glucose, GlutaMax ${ }^{\mathrm{TM}}$ (Thermo Fisher Scientific, catalog number: 10566016) supplemented with 10\% (v/v) heat-inactivated Fetal Bovine Serum (Sigma-Aldrich, catalog number: F7524)

7. DPBS $1 \times$ (Thermo Fisher Scientific, catalog number: 14190144)

8. $0.05 \%$ Trypsin-EDTA $1 x$ (Thermo Fisher Scientific, catalog number: 25300054) 
9. Heat-inactivated Fetal Bovine Serum (Sigma-Aldrich, catalog number: F7524) (see Recipes for heat-inactivation)

B. Bacteria culture

1. Inoculating loops (SARSTEDT, catalog number: 86.1562.010)

2. Falcon ${ }^{\circledR} 14 \mathrm{ml}$ round bottom tube with snap cap (Corning, catalog number: 352006 )

3. Round Petri plate (Corning, Gosselin ${ }^{\mathrm{TM}}$, catalog number: BP93B-102)

4. Bacterial glycerol stock, stored at $-80^{\circ} \mathrm{C}$ (lab collection)

a. SL1344 pM965, expressing GFP under the rpsM promoter. The strain was obtained after transformation of SL1344 with the pM965 plasmid described by Stecher and colleagues (Stecher et al., 2004). See Recipes for transformation.

b. SL1344 pGG2, expressing dsRed under the rpsM promoter. The strain was obtained after transformation of SL1344 with the pGG2 plasmid described by Lelouard and colleagues (Lelouard et al., 2010). See Recipes for transformation.

5. Electroporation Cuvettes (Bio-Rad Laboratories, catalog number: 1652086)

6. Ampicillin (Sigma-Aldrich, catalog number: A9393) (Keep the stock solution of $50 \mathrm{mg} / \mathrm{ml}$ at $\left.20^{\circ} \mathrm{C}\right)$

7. Tryptone (BD, catalog number: 211705)

8. Yeast Extract (BD, catalog number: 212750)

9. $\mathrm{NaCl}$ (Sigma-Aldrich, catalog number: 746398)

10. LB agar plate containing Ampicillin at $100 \mu \mathrm{g} / \mathrm{ml}$ (homemade, see Recipes)

11. Lysogeny broth (LB) medium supplemented with $0.3 \mathrm{M} \mathrm{NaCl}$ (homemade, see Recipes)

C. Infection

1. $1.5 \mathrm{ml}$ Eppendorf safe-lock tubes (Eppendorf, catalog number: 0030120086)

2. Semi-micro disposable cuvettes (BRAND, catalog number: 759105)

3. Parafilm ${ }^{\circledR} \mathrm{M}$ sealing tape (Sigma-Aldrich, Parafilm, catalog number: P7543)

4. Pipetting reservoir, $25 \mathrm{ml}$ (Thermo Fisher Scientific, catalog number: 10717964)

5. Filter tips, $200 \mu \mathrm{l}$ (Sorenson Bioscience, catalog number: 035230)

6. Gentamicin solution (Sigma-Aldrich, catalog number: G1397) (Keep the stock solution of 50 $\mathrm{mg} / \mathrm{ml}$ at $-20^{\circ} \mathrm{C}$ )

7. $\mathrm{NaCl}$ (Sigma-Aldrich, catalog number: 746398 )

8. $\mathrm{KCl}$ (Thermo Fisher Scientific, catalog number: 13305)

9. $\mathrm{CaCl}_{2}$ (Sigma-Aldrich, catalog number: 449709)

10. $\mathrm{MgCl}_{2}$ (Sigma-Aldrich, catalog number: $\mathrm{M} 8266$ )

11. Glucose (Sigma-Aldrich, catalog number: G8270)

12. HEPES (Sigma-Aldrich, catalog number: H3375)

13. Heat-inactivated Fetal Bovine Serum (Sigma-Aldrich, catalog number: F7524) (see Recipes for heat-inactivation) 
14. 20x EM medium (homemade, see Recipes)

15. 1x EM medium (see Recipes)

D. Fixation

1. Aluminum foil

2. Paraformaldehyde $16 \%$ solution (Electron Microscopy Sciences, catalog number: 15710)

3. DPBS $1 x$ (Thermo Fisher Scientific, catalog number: 14190144)

E. Staining

1. CellMask ${ }^{\mathrm{TM}}$ Deep Red Plasma Membrane Stain (Thermo Fisher Scientific, catalog number: C10046)

2. DAPI (Thermo Fisher Scientific, catalog number: D1306) (stock solution at $10 \mathrm{mg} / \mathrm{ml} \mathrm{stored} \mathrm{at} \mathrm{-}$ $\left.20^{\circ} \mathrm{C}\right)$

3. DPBS 1x (Thermo Fisher Scientific, catalog number: 14190144)

\section{Equipment}

1. Single-channel pipettes (Eppendorf, model: Research ${ }^{\circledR}$ plus)

2. Multichannel Pipette, 30 to $300 \mu \mathrm{l}$ (Thermo Fisher Scientific, catalog number: $4661030 \mathrm{~N}$ )

3. Pipet Filler (Thermo Fisher Scientific, catalog number: 9501)

4. Inverted Microscope (Motic, model: AE2000)

5. Laminar hood (Thermo Fisher Scientific, model: 1300 Series Class II Type A2)

6. Incubator set at $37^{\circ} \mathrm{C}, 5 \% \mathrm{CO}_{2}$ (Thermo Fisher Scientific, catalog number: NC0689918)

7. Centrifuge $5810 / 5810 \mathrm{R}$ (Eppendorf, model: $5810 / 5810 \mathrm{R}$ )

8. Incubator with orbital shaker (INFORS, Multitron no series 112569-3)

9. Water Bath (JULABO, model: TW12, catalog number: 9550112)

10. Thermomixer compact (Eppendorf, model: ThermoMixer $^{\circledR} \mathrm{C}$ )

11. Photometer (Eppendorf, AG 22331)

12. Centrifuge 5424/ 5424 R (Eppendorf, model: $5424 / 5424$ R)

13. Fume hood (SORBONNE ASPRIL/1000)

14. Inverted widefield microscope equipped with a $20 \times / 0.5 \mathrm{NA}$ air objective, an automatic programmable XY-stage, and a focusing system (Nikon), a CoolSnap2 camera (Roeper Scientific), a mercury lamp and the following filter cubes: DAPI (Excitation filter: 387/11, Emission filter: 447/60), FITC (Excitation filter: 482/35, Emission filter: 536/40), TRITC (Excitation filter: 543/22, Emission filter: 593/40) Cy5 (Excitation filter: 628/40, Emission filter: 692/40)

15. $250 \mathrm{ml}$ Erlenmeyer flask

16. Electroporation Systems (Bio-Rad Laboratories, model: Gene Pulser Xcell ${ }^{\mathrm{TM}}$ )

17. Double boiler: $2 \mathrm{~L}$ beaker filled with $600 \mathrm{ml}$ water 
18. Microwave

\section{Software}

1. NIS-Elements Microscope Imaging Software (Nikon)

2. Icy (Copyright 2011 Institut Pasteur, Icy is free software under the terms of the GNU General Public License, http://icy.bioimageanalysis.org)

3. $R(R$ is free software under the terms of the GNU General Public License, https://www.rproject.org/). The code available in the data analysis part has been written with $R$, version 3.4.2

4. GraphPad Prism version 7.00 for Windows, GraphPad Software (La Jolla California USA, www.graphpad.com)

\section{Procedure}

Note: HeLa cells and bacteria should be handled under a sterile laminar BSL-Il hood, unless otherwise mentioned. This protocol describes fluorophore-expressing Salmonella infection of HeLa cells but can be adapted for other cell lines and pathogens. In particular, non-fluorescent pathogens can also be labeled by immunofluorescence.

A. Culture of bacteria 2 days before infection

1. Take out a vial of glycerol stock of the bacteria SL1344-pGG2 (dsRed) and SL1344-pM965 (GFP) stored at $-80^{\circ} \mathrm{C}$.

2. Strike the bacteria on an LB agar plate containing the appropriate antibiotics (here ampicillin) to allow the formation of single colonies with both strains.

3. Incubate the bacteria at $37^{\circ} \mathrm{C}$ overnight.

4. The next day, store the plate at $4{ }^{\circ} \mathrm{C}$. The Petri dishes can be kept up to one week (Figure 1 , see Note 1). 


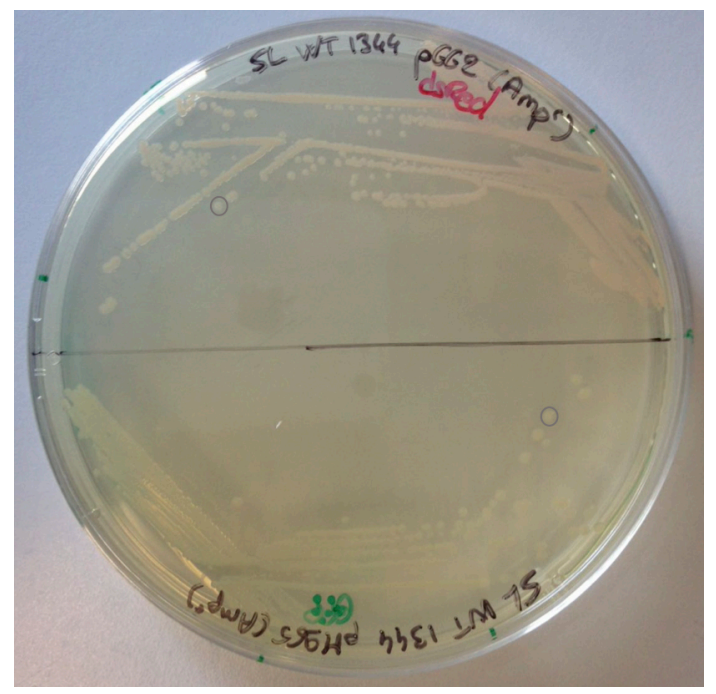

Figure 1. Bacterial culture on Petri dish. SL1344-pGG2 (dsRed) and SL1344-pM965 (GFP) are struck on a Petri dish containing the antibiotics (ampicillin). Individual colonies are circled in grey.

B. Culture of bacteria 1 day before infection

1. Fill two Falcon $14 \mathrm{ml}$ polypropylene round-bottom tubes with $3 \mathrm{ml}$ of LB medium supplemented with $0.3 \mathrm{M} \mathrm{NaCl}$ and ampicillin at $50 \mu \mathrm{g} / \mathrm{ml}$.

2. Pick 3 colonies of one strain from the Petri dish using the same inoculation loop and add them into a first tube. Repeat this step with the second strain in a second tube.

3. Incubate at $37^{\circ} \mathrm{C}$ under agitation ( $220 \mathrm{rpm}$ ) in a $45^{\circ}$-tilted rack overnight (see Note 2 ).

C. Culture of cells 1 day before infection

1. Use a water-bath to pre-warm the medium (trypsin, DMEM $+10 \%$ FBS, DPBS $1 \mathrm{x}$ ) at $37^{\circ} \mathrm{C}$.

2. Take a tissue culture flask of $75 \mathrm{~cm}^{2}$ containing HeLa cells at about $80 \%$ confluency based on microscopic observation of the cell density.

3. Wash the cells with $5 \mathrm{ml}$ of warm PBS 1x.

4. Add $5 \mathrm{ml}$ of warm $0.05 \%$ trypsin-EDTA and incubate the cells for $5 \mathrm{~min}$ in an incubator at $37^{\circ} \mathrm{C}$, $5 \% \mathrm{CO}_{2}$.

5. Detach the remaining attached cells by carefully hitting the flask on the side and moving the medium along the surface of the flask.

6. Check the efficiency of the trypsin action under the microscope: the cells should be round and fully detached from the surface of the flask. Incubate longer if necessary.

7. Stop the trypsin action by adding $5 \mathrm{ml}$ DMEM $+10 \%$ FBS.

8. Resuspend the cells and transfer all the content of the flask into a $15 \mathrm{ml}$ Falcon ${ }^{\circledast}$ tube.

9. Centrifuge the cells for $4 \mathrm{~min}$ at $200 \times \mathrm{g}$ using Centrifuge $5810 / 5810 \mathrm{R}$ (see Note 3).

10. Discard the supernatant.

11. Resuspend the cell pellet in warm DMEM $+10 \%$ FBS medium.

12. Transfer $15 \mu$ l of the cell suspension into a cell counter chamber. 
13. Count the cells in the cell counter chamber using a bench microscope and a cell counter.

14. Calculate the initial cell concentration (Ci).

15. Calculate the volume of cells needed (Vi) to obtain a final concentration (Cf) of $1.5 \times 10^{4}$ cells $/ \mathrm{ml}$ in a final volume (Vf) of $2 \mathrm{ml}$. Use the following formula:

$$
\mathrm{Vi}=\mathrm{Cf} \times \mathrm{Vf} / \mathrm{Ci}
$$

16. Dilute the cells in DMEM $+10 \%$ FBS medium in a new Falcon ${ }^{\circledR}$ tube.

17. Take a 96-well cell culture microplate and label the plate map. In the following part of the protocol, we consider using 16 wells of the plate (see Note 4, Figure 2).

18. Add $100 \mu \mathrm{l}$ of the cell dilution per well.

19. Add $100 \mu$ of PBS (1x) in the wells surrounding the cells (see Note 4, Figure 2).

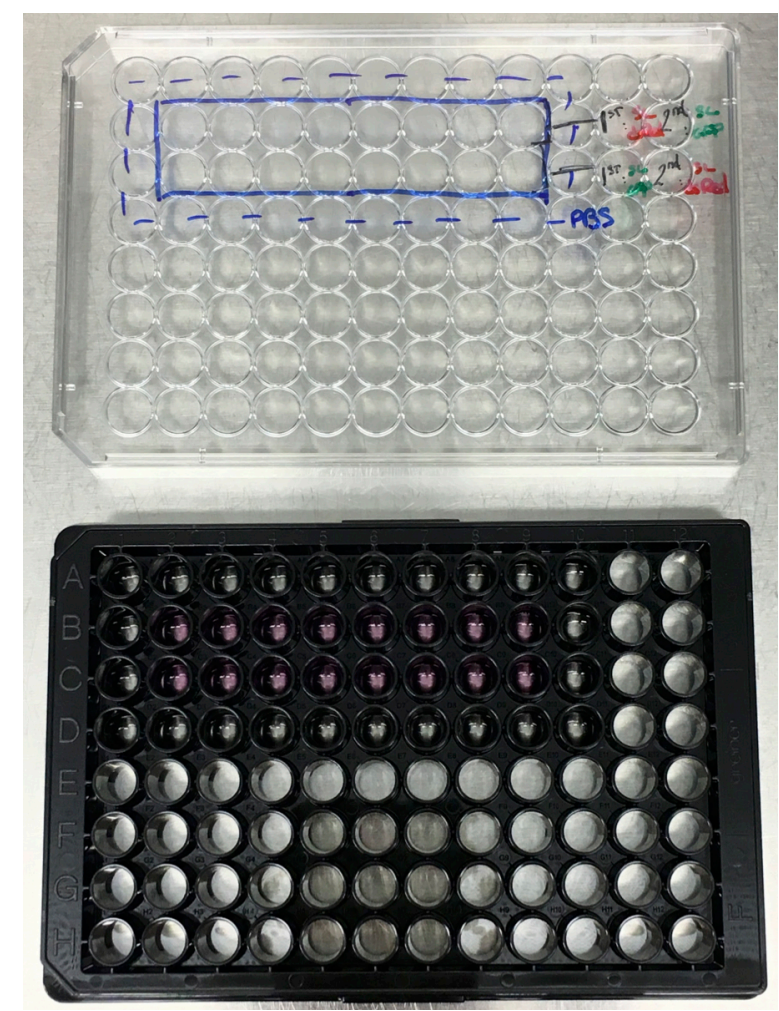

Figure 2. Cell culture in 96-well plate. The cells occupy the wells B2 to B9 and C2 to C9. The surrounding wells are filled with PBS 1x (see Note 4).

20. Keep the 96 -well plate in the incubator at $37^{\circ} \mathrm{C}, 5 \% \mathrm{CO}_{2}$ for $24 \mathrm{~h}$.

D. Infection

1. Make a subculture for each bacterial strain by diluting $150 \mu \mathrm{l}$ of the overnight bacterial culture in $3 \mathrm{ml}$ of LB medium supplemented with $0.3 \mathrm{M} \mathrm{NaCl}$ and $50 \mu \mathrm{g} / \mathrm{ml}$ ampicillin (dilution 1:21). 
2. Incubate the subcultures for $3 \mathrm{~h}$ in a $45^{\circ}$-tilted rack of an incubator at $37^{\circ} \mathrm{C}$ with an orbital shaker at $220 \mathrm{rpm}$ (see Note 5).

Important: Steps D1 and D2 should be repeated $3 \mathrm{~h}$ later to prepare the subculture necessary for the second infection.

3. Under a laminar hood, prepare $4 \mathrm{ml}$ of "Gent100" solution containing EM medium supplemented with $10 \%$ FBS and gentamicin at $100 \mu \mathrm{g} / \mathrm{ml}$.

Note: Mix $400 \mu \mathrm{l}$ of FBS with $8 \mu \mathrm{l}$ of gentamicin at $50 \mathrm{mg} / \mathrm{ml}$ and complete with 3,592 $\mu \mathrm{l}$ of EM.

4. Under a laminar hood, prepare $2 \mathrm{ml}$ of "Gent10" solution containing EM medium supplemented with $10 \%$ FBS and gentamicin at $10 \mu \mathrm{g} / \mathrm{ml}$.

Note: Mix $200 \mu \mathrm{l}$ of FBS with $0.8 \mu \mathrm{l}$ of gentamicin at $50 \mathrm{mg} / \mathrm{ml}$ and complete with 1,799.2 $\mu \mathrm{l} \mathrm{of}$ EM.

5. Use the water-bath to prewarm the EM medium, the Gent100 and Gent10 solutions to $37^{\circ} \mathrm{C}$.

6. Use the thermomixer to pre-warm four empty Eppendorf tubes at $37^{\circ} \mathrm{C}$.

7. At the end of the $3 \mathrm{~h}$ of incubation, dilute $100 \mu \mathrm{l}$ of the bacterial subculture in $400 \mu \mathrm{l}$ of LB medium (volume final $500 \mu$, dilution 1:5), transfer the dilutions into two semi-micro disposable cuvettes, seal them with parafilm and measure the OD using the photometer. The OD of the dilutions should be around 0.4 , corresponding to the late log phase of the bacterial growth.

8. Prepare the HeLa cells for the infection by removing the DMEM $+10 \%$ FBS medium from the cell wells and add $100 \mu \mathrm{l}$ of EM medium per well. Keep the plate at $37{ }^{\circ} \mathrm{C}, 5 \% \mathrm{CO}_{2}$ until the infection.

9. Transfer $500 \mu \mathrm{l}$ of the two bacterial subculture from Step D2 into warmed one empty Eppendorf tube each.

10. Centrifuge the Eppendorf tubes using Centrifuge $5424 / 5424 \mathrm{R}$ for $1 \mathrm{~min}$, at $7,600 \times \mathrm{g}$.

11. Discard the supernatant and resuspend the bacterial pellet in $500 \mu \mathrm{l}$ warm EM medium.

12. Centrifuge again the Eppendorf tubes (washing step) for $1 \mathrm{~min}$, at 7,600 $\mathrm{xg}$.

13. Discard the supernatant and resuspend the bacterial pellet in $500 \mu \mathrm{l}$ warm EM.

14. Dilute $100 \mu \mathrm{l}$ of the bacterial suspension in $400 \mu \mathrm{l}$ of EM medium (final volume $500 \mu \mathrm{l}$, dilution 1:5). Transfer the dilutions into two semi-micro disposable cuvettes and measure the OD using the photometer.

15. Calculate the dilution for a final multiplicity of infection (MOI) of 30 , using the following calculation method:

a. Wanted concentration of bacteria (Cf):

$$
\begin{aligned}
30 \times\left(3.5 \times 10^{4} \text { cells } / \text { well }\right) & =1.05 \times 10^{6} \text { bacteria } / \text { well } \\
& =1.05 \times 10^{7} \text { bacteria } / \mathrm{ml}
\end{aligned}
$$

b. Initial volume to collect (Vi) for a final volume (Vf) of $0.5 \mathrm{ml}$ :

$$
\begin{aligned}
V i & =(\mathrm{Cf} \times \mathrm{Vf}) / \mathrm{Ci} \\
V i & =\left(1.05 \times 10^{7} \times 0.5\right) /\left(\mathrm{OD} \times 5 \times 10^{9}\right)
\end{aligned}
$$


16. Prepare the two dilutions in the two remaining empty warm Eppendorf tubes for SL1344-pGG2 (dsRed) and SL1344-pM965 (GFP) completing the volume with warm EM (see Note 6).

17. Remove the medium from each well of the 96-well plate using the multichannel pipette.

18. Add $50 \mu \mathrm{l}$ of the bacterial dilution into each well according to the map of the plate (Figure 3 ).

\begin{tabular}{|l|l|l|l|l|l|l|l|l|}
\hline DPBS & DPBS & DPBS & DPBS & DPBS & DPBS & DPBS & DPBS & DPBS \\
\hline DPBS & SL-dsRed & SL-dsRed & SL-dsRed & SL-dsRed & SL-dsRed & SL-dsRed & SL-dsRed & DPBS \\
\hline DPBS & SL-GFP & SL-GFP & SL-GFP & SL-GFP & SL-GFP & SL-GFP & SL-GFP & DPBS \\
\hline DPBS & DPBS & DPBS & DPBS & DPBS & DPBS & DPBS & DPBS & DPBS \\
\hline
\end{tabular}

Figure 3. Infection map of a 96-well plate. First round of infection.

19. Incubate the 96 -well plate for $30 \mathrm{~min}$ in an incubator at $37^{\circ} \mathrm{C}, 5 \% \mathrm{CO}_{2}$.

20. Using the multichannel pipette and the pipetting reservoir, wash each well 3 times using $100 \mu \mathrm{l}$ of warm EM each (Figure 4).

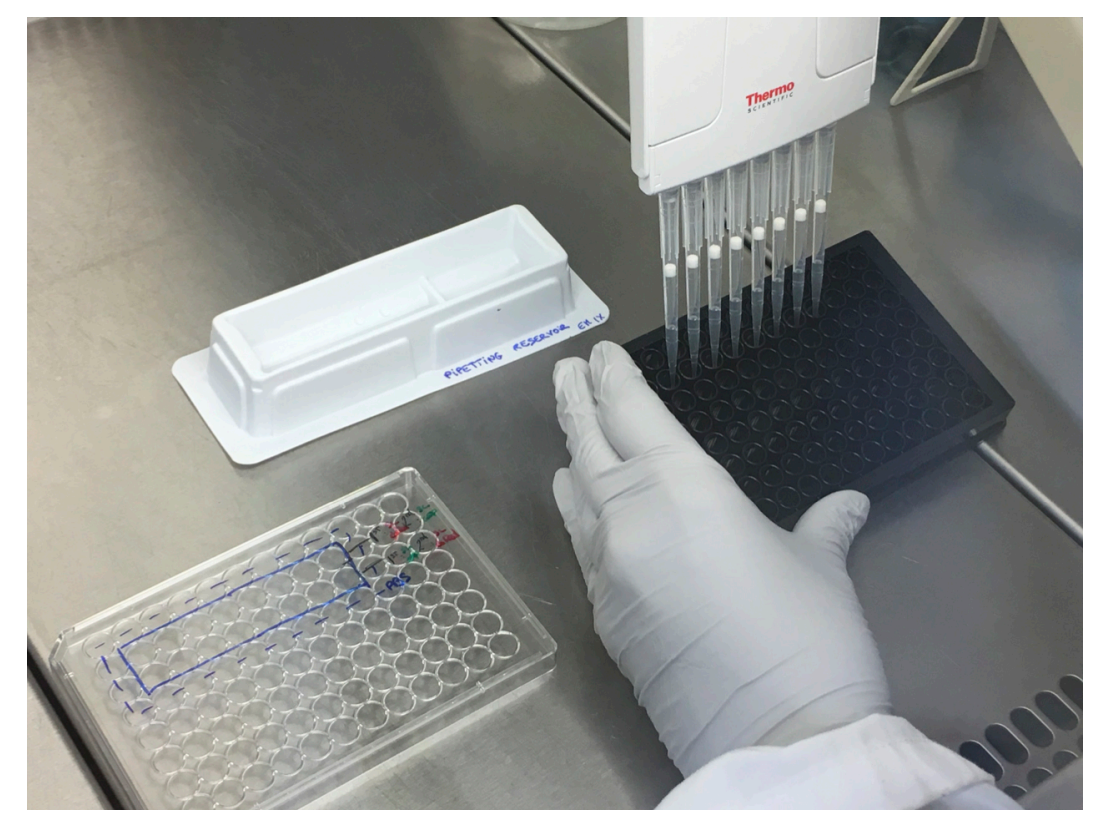

Figure 4. Washing step using the multichannel pipette and the pipetting reservoir

21. Change the medium to $100 \mu \mathrm{l}$ of Gent100 solution in each well.

22. Incubate the cells for $1 \mathrm{~h}$ in an incubator at $37^{\circ} \mathrm{C}, 5 \% \mathrm{CO}_{2}$.

23. Change the medium to $100 \mu \mathrm{l}$ of Gent10 solution in each well (see Note 7).

24. Incubate the cells for $1 \mathrm{~h}$ in an incubator at $37^{\circ} \mathrm{C}, 5 \% \mathrm{CO}_{2}$.

25. Wash the cells twice each with $100 \mu \mathrm{l}$ of warm EM medium to remove the remaining gentamicin.

26. Proceed to the second infection following the Steps D6 to D22 and using the second infection map (Figure 5). 


\begin{tabular}{|l|l|l|l|l|l|l|l|l|}
\hline DPBS & DPBS & DPBS & DPBS & DPBS & DPBS & DPBS & DPBS & DPBS \\
\hline DPBS & SL-GFP & SL-GFP & SL-GFP & SL-GFP & SL-GFP & SL-GFP & SL-GFP & DPBS \\
\hline DPBS & SL-dsRed & SL-dsRed & SL-dsRed & SL-dsRed & SL-dsRed & SL-dsRed & SL-dsRed & DPBS \\
\hline DPBS & DPBS & DPBS & DPBS & DPBS & DPBS & DPBS & DPBS & DPBS \\
\hline
\end{tabular}

Figure 5. Infection map of a 96-well plate. Second round of infection.

E. Fixation (under fume hood)

1. Prepare $700 \mu$ l of $4 \%$ PFA by diluting the $16 \%$ PFA in DPBS $1 x$.

2. Remove the medium from each well of the 96-well plate and add $40 \mu \mathrm{l}$ of $4 \%$ PFA into each well.

3. Incubate the plate for $15 \mathrm{~min}$ at room temperature (RT). From this step, protect the plate from light using aluminum foil.

4. Remove the PFA and wash 3 times each with $100 \mu$ of DPBS using the multichannel pipette and pipetting reservoir.

F. Staining

1. Dilute CellMask at 1:1,000 and DAPI at 1:1,000 in $1 \mathrm{ml}$ of DPBS to make a "staining mix".

2. Add $40 \mu \mathrm{l}$ of the staining mix per well and incubate for $20 \mathrm{~min}$ at RT.

3. Wash the wells 3 times with $100 \mu \mathrm{l}$ of DPBS using the multichannel pipette and the pipetting reservoir.

4. Keep the plate at $4{ }^{\circ} \mathrm{C}$ with $100 \mu \mathrm{l}$ of DPBS per well, protected from light (with an aluminum foil) until acquisition at the microscope (see Note 8).

G. Automatic microscopic image acquisition

1. Acquire the images of the 96-well plate using the Nikon inverted widefield microscope equipped with a 20x/0.5NA air objective, and the NIS software.

2. Using JOBS Explorer, set an automatic acquisition pipeline such as presented in Figures 6 to 12:

a. Give a name to the pipeline and select the type of storage as .nd2 (Figure 6). 


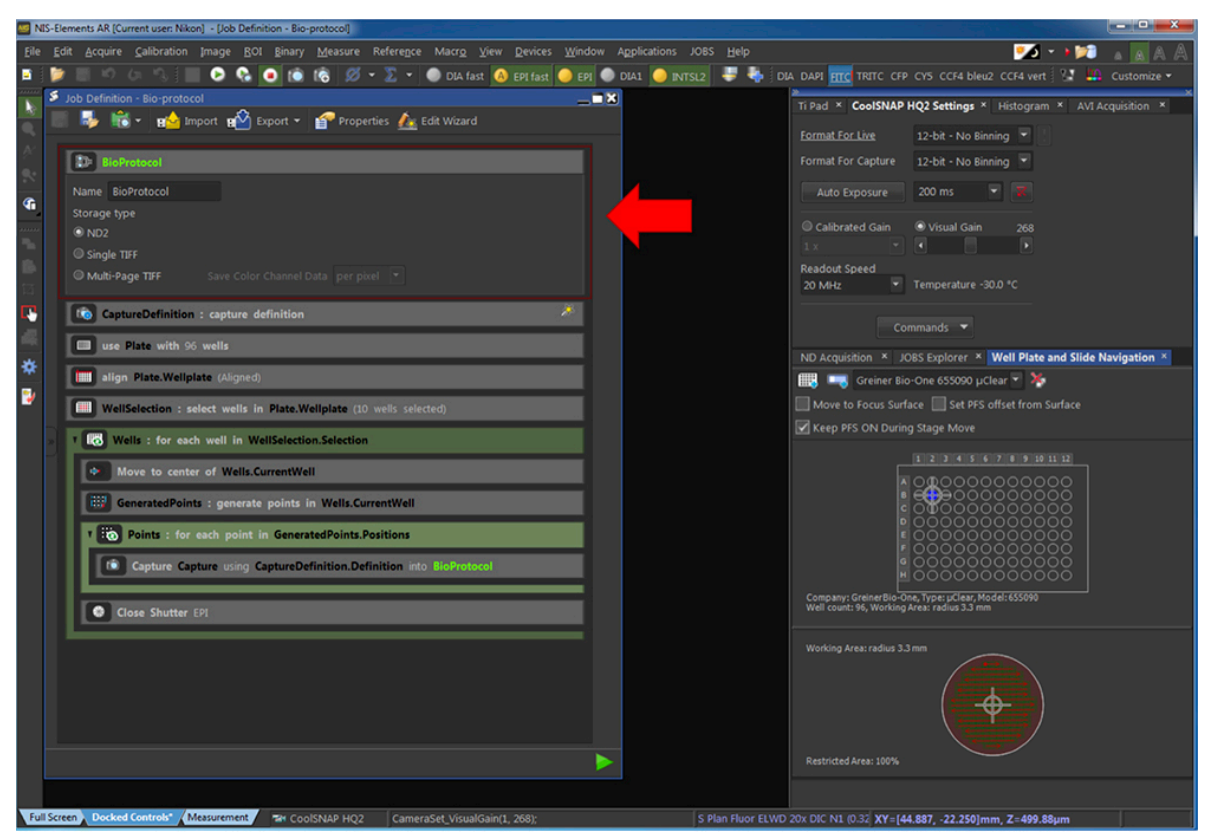

Figure 6. Creation of an automatic pipeline of acquisition. The red arrow points at the part of the pipeline related to the Step G2a.

b. Define the channel to capture (Figure 7). The time of exposure appears identical as in the "CoolSNAP HQ2 Settings" panel. It needs to be adapted for each experiment.

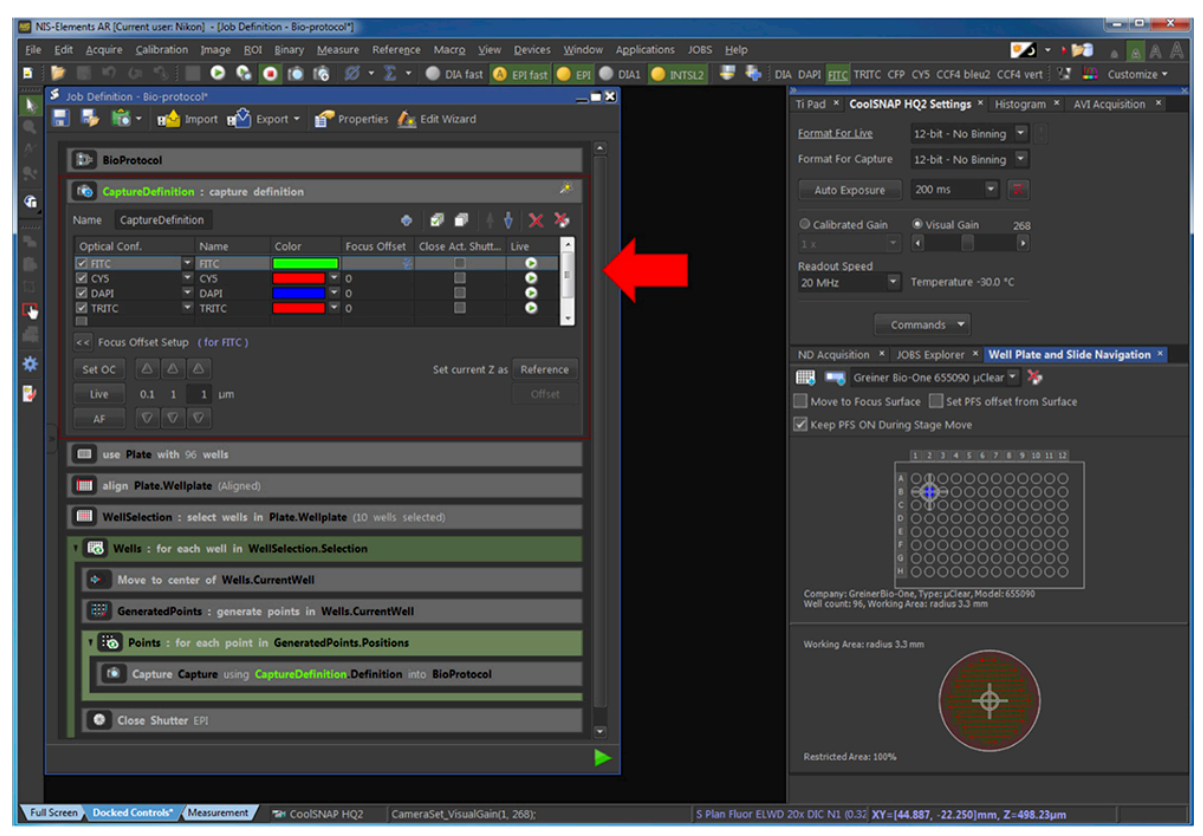

Figure 7. Definition of the parameters used for image capture. The red arrow points at the part of the pipeline related to the Step G2b.

C. Select the type of plate used by selecting it from a list of reference clicking on "Select from DB..." or by defining the plate characteristic by clicking on "Custom Well Plate" (Figure 8). 


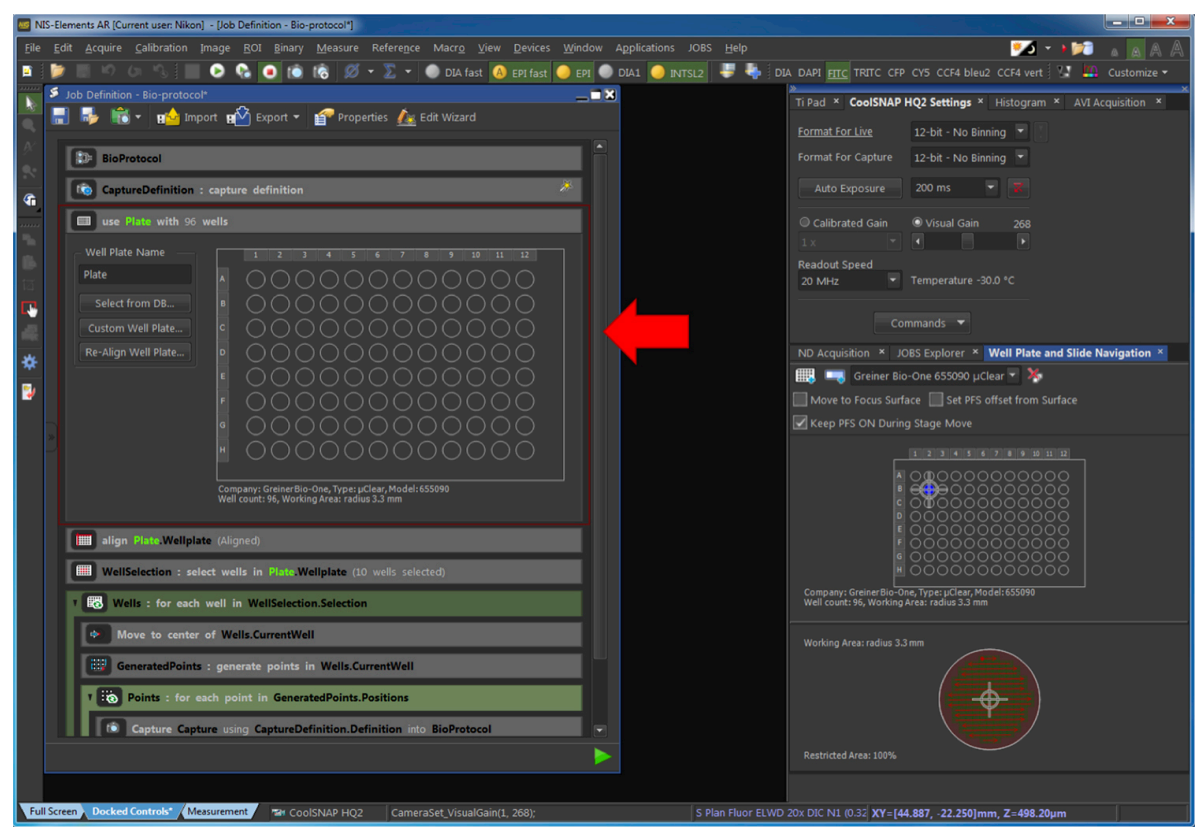

Figure 8. Selection of the type of plate used. The red arrow points at the part of the pipeline related to the Step G2c.

d. Align the plate by defining the border of 3 wells of the plate (Figure 9).

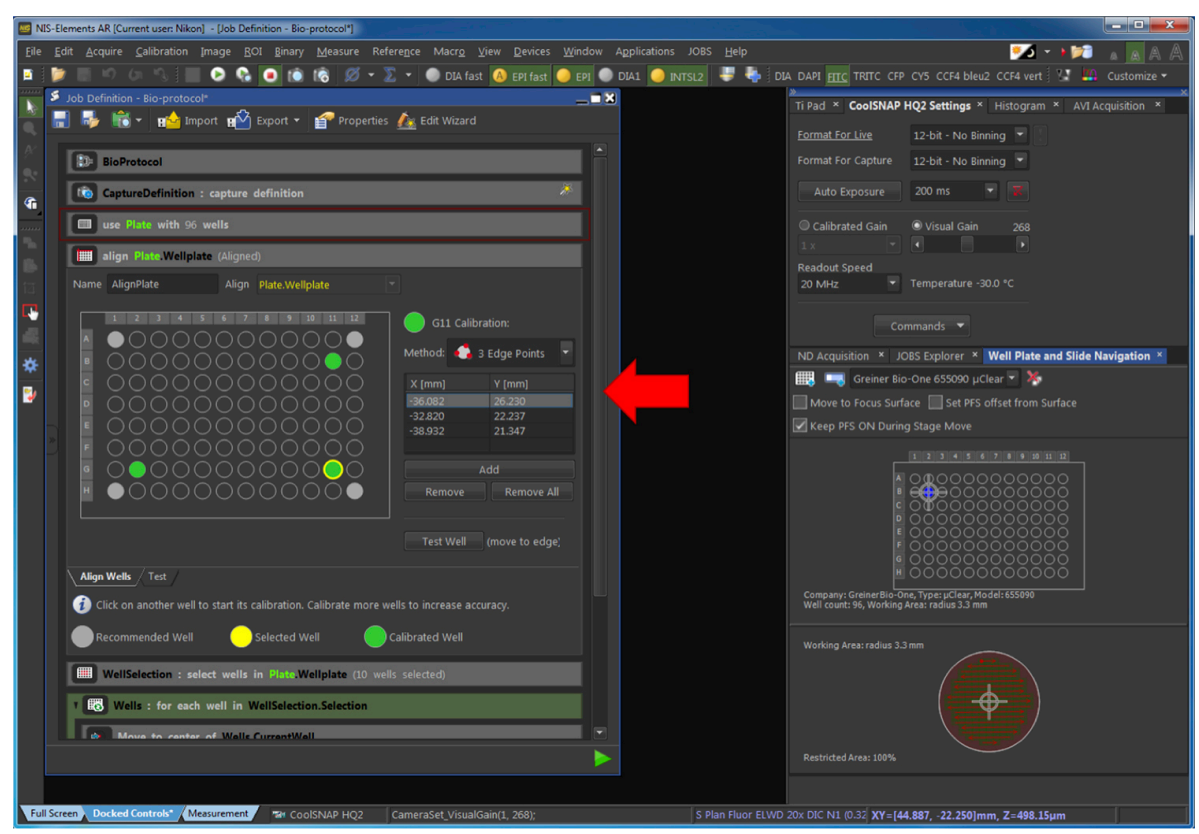

Figure 9. Alignment of the plate. The red arrow points at the part of the pipeline related to the Step G2d.

e. Select the wells of the plate to be acquired (Figure 10). 


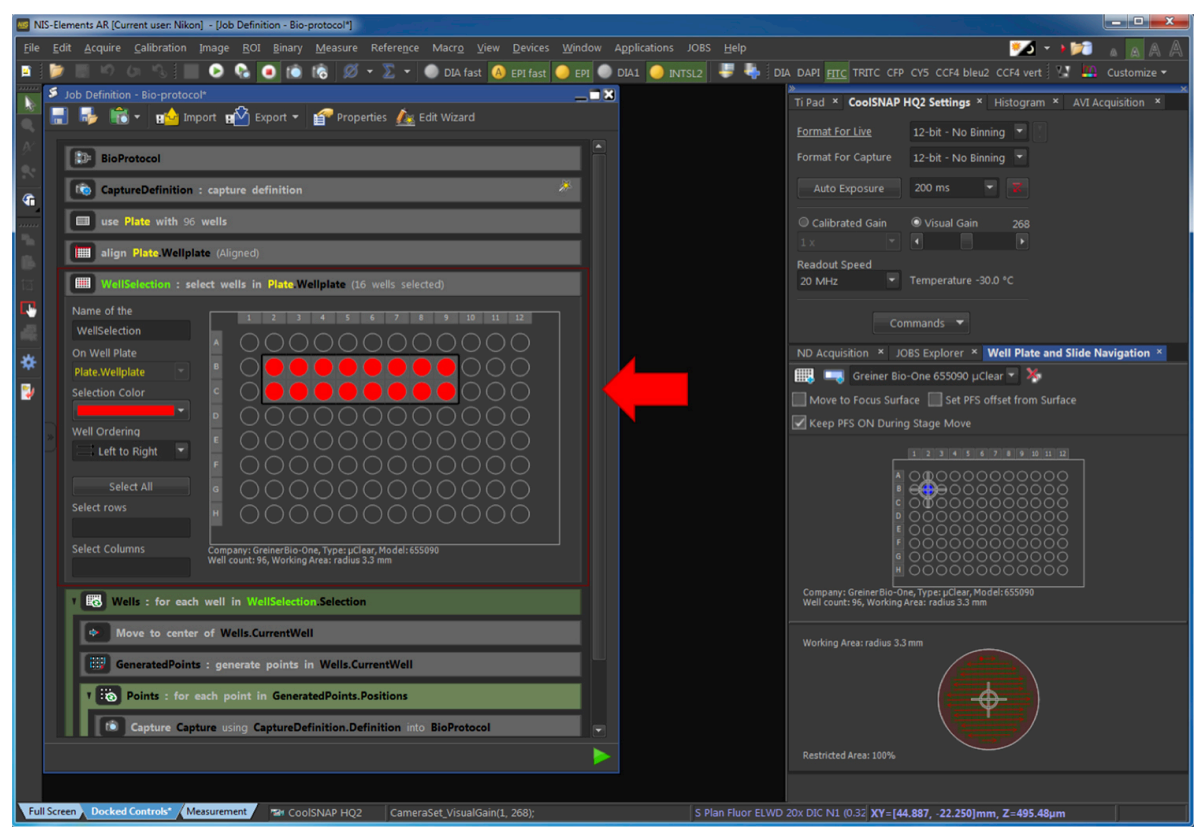

Figure 10. Selection of the wells to be acquired. The red arrow points at the part of the pipeline related to the Step G2e.

f. Generate the fields of view to be acquired (Figure 11).

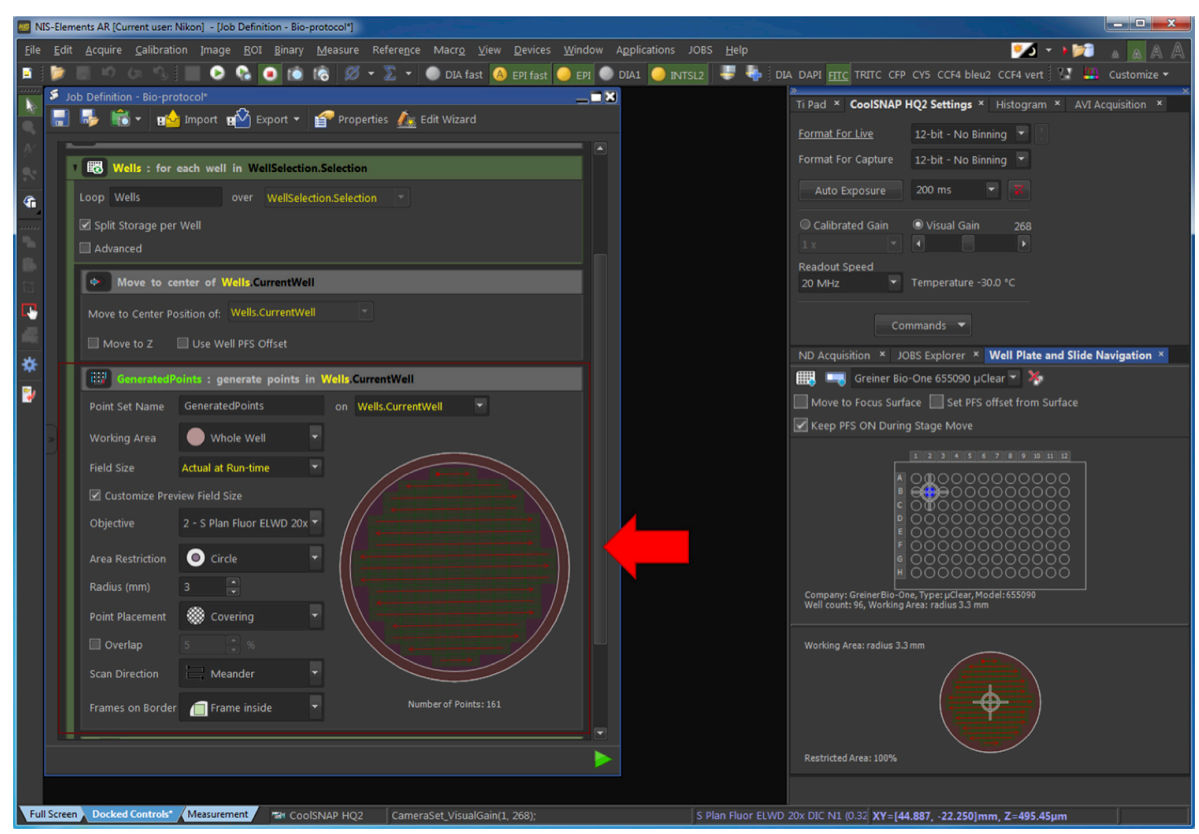

Figure 11. Generation of the fields to be acquired. The red arrow points at the part of the pipeline related to the Step G2f.

g. Select the parameters of image capture as presented in Figure 12. 


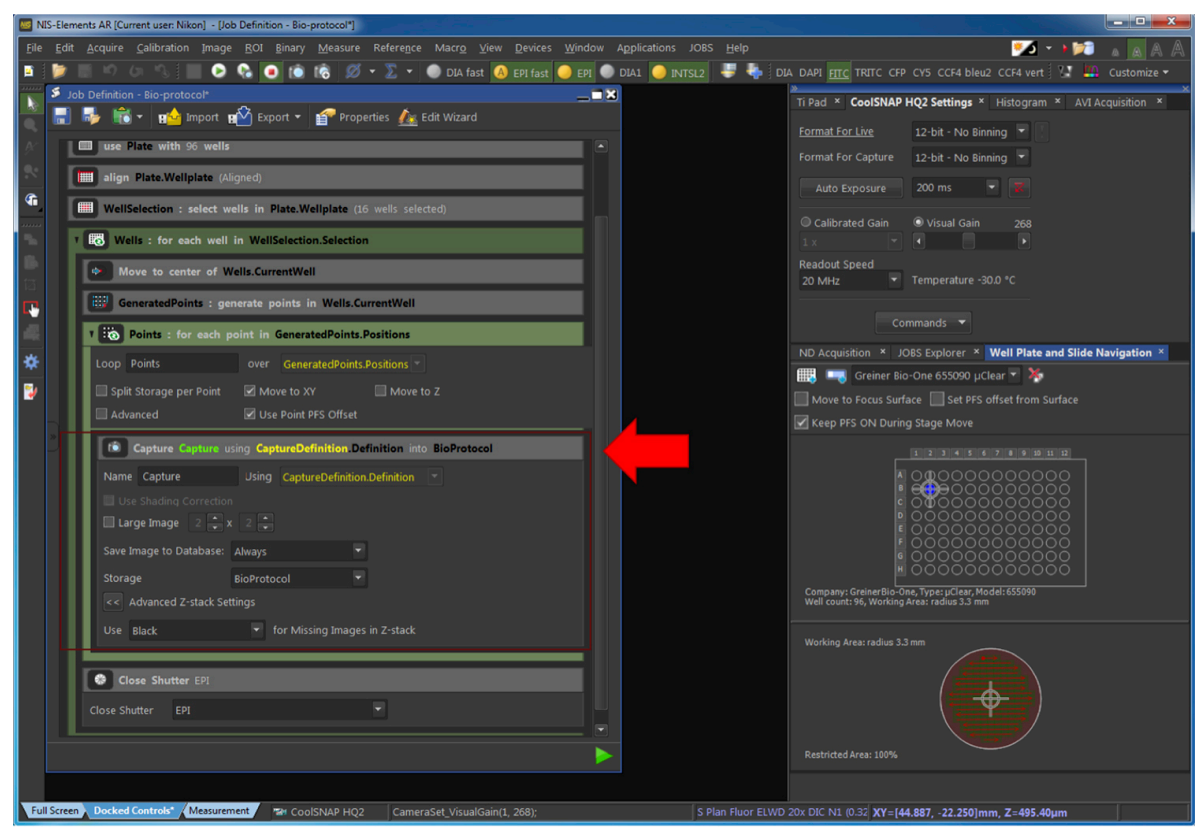

Figure 12. Definition of the capture process. The red arrow points at the part of the pipeline related to the Step G2g.

h. Run the acquisition. The time of acquisition varies depending on the number of wells and the number of positions per well to be acquired and commonly lasts for several hours. The files are saved automatically. An example of the obtained images is provided in Figure 1 of the associated publication (Voznica et al., 2018).

\section{Data analysis}

\section{A. Automatic image segmentation}

Icy is open-source software for image processing developed by the Biolmage Analysis team at Institut Pasteur (de Chaumont et al., 2012) and is available online (http://icy.bioimageanalysis.org). Its graphic interface, called "Protocols", enables to create pipelines for image processing.

The integral pipeline described below can be downloaded here. To obtain precise results, all detection parameters need to be adjusted between experiments to balance potential variation between acquisitions (see Note 9). An example of the obtained image segmentation is provided in Figure S5 of the associated publication (Voznica et al., 2018).

Each processing step is represented as a "Block" that can be linked together (Figure 13). Each identified object is called "Region of Interest" (ROI). An output from one block, for instance a list of ROls, is generally used as an input for another block (see Note 10).

1. General architecture of the pipeline and iterations

a. Use "Folder" block to set the folder of origin that contains the image sets. Its output goes to "File batch" block. 
b. Use "File batch" block to execute the pipeline over all image sets contained in the original folder. "File batch" contains the blocks "Append file name" and "Sequence series batch." "Sequence series batch" contains blocks for all following steps of analysis.

c. Use "Append file name" block to store the name of the file. This is used for naming the output file.

d. Use "Sequence series batch" to execute image processing on each acquired field of view, further called "image series". Each image series contains 4 channels: the DAPI channel containing nucleus, the FITC channel containing GFP-Salmonella, the TRITC channel containing dsRed-Salmonella and the Cy5 channel containing HeLa cells labeled with CellMask.

e. Use "Integer" block to store the number of the image series to be analyzed. This is used to identify cells from the same image.

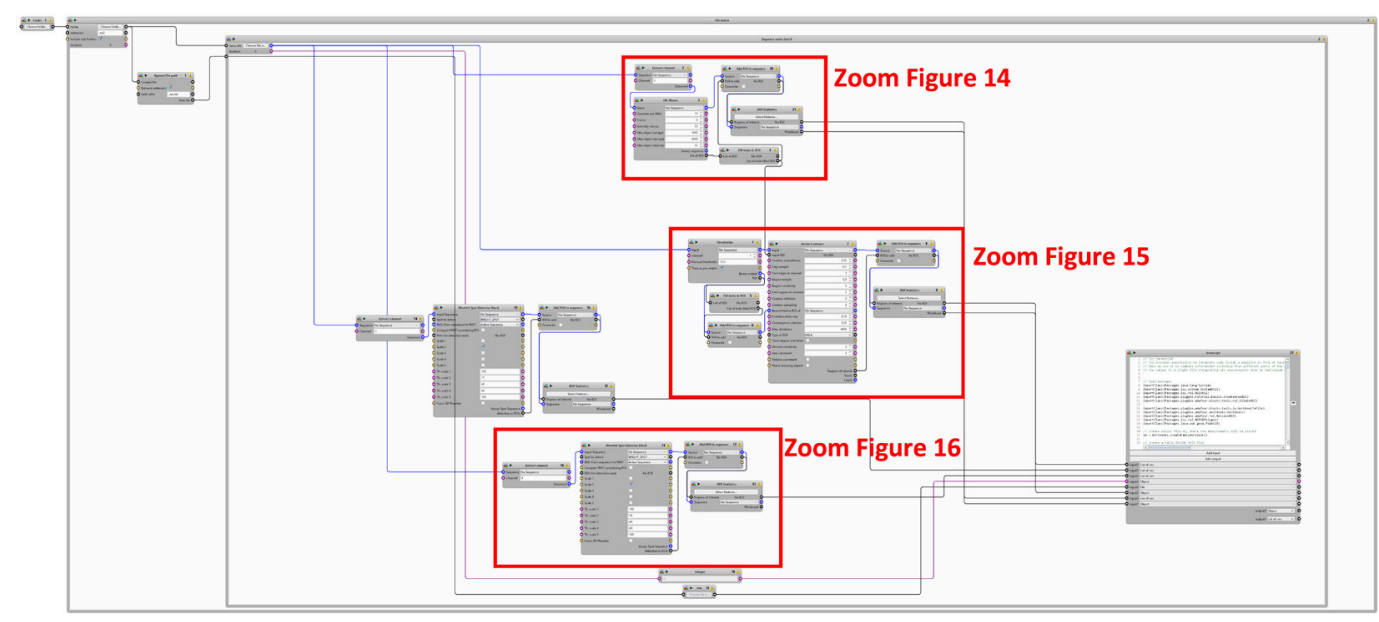

Figure 13. General architecture of the pipeline

2. Identification of individual nuclei from the DAPI channel (Figure 14)

a. Use "Extract channel" block to extract the DAPI channel from image series. Its output goes to "HK-means" block.

b. Use "HK-means" block to segment image into ROI (here nuclei) within a certain size range.

c. Use "Fill holes in ROI" block to obtain complete nuclei without holes. The ROI output is used for the blocks "Add ROI to sequence" and "Active contours" that are further used to segment individual cells.

d. Use "Add ROI to sequence" to convert newly created ROls to a binary image. This binary image is used as the input of the block "ROI statistics".

e. Use "ROI statistics" to measure different features of these nuclei (XY-position, etc.). 


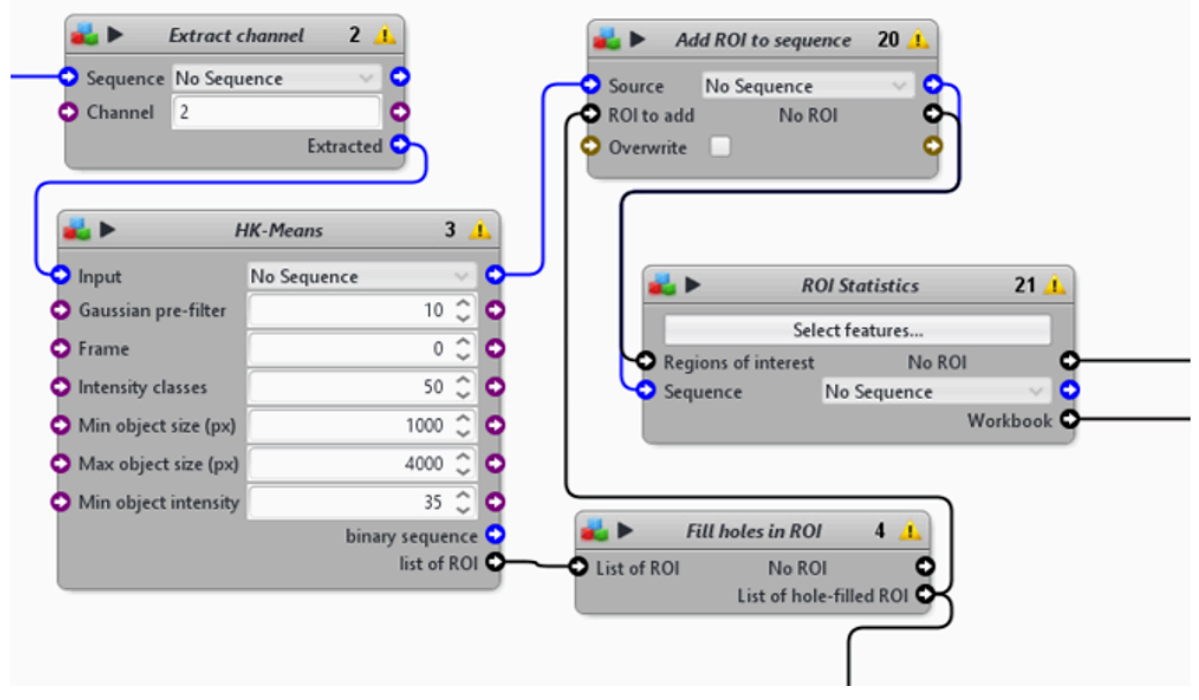

Figure 14. A first section from the automatic image-processing pipeline. From DAPI channel extraction to the measurements of nuclei statistics.

3. Identification of individual cells from the Cy5 channel (Figure 15)

a. Use "Active Contours" block to segment individual cells. The algorithm uses the ROI previously detected for the nuclei as initial cell ROI, which is expanded until the detection of the cell border.

b. The "Active Contours" block requires a binary image with a determined threshold. Use "Thresholder" block to create a filtered binary image from the Cy5 channel and to identify cellular ROls. Complete the binary image with a "Fill Holes in ROI" and "Add ROI to sequence" blocks. This image is used as the input for the "Bound field to ROI" step of the "Active Contours" block.

c. Adapt the different detection parameters to the image (see Note 11).

d. Use the blocks "add ROI to sequence" and "ROI statistics" to measure different features of these cells (XY-position, size, shape, etc.). 


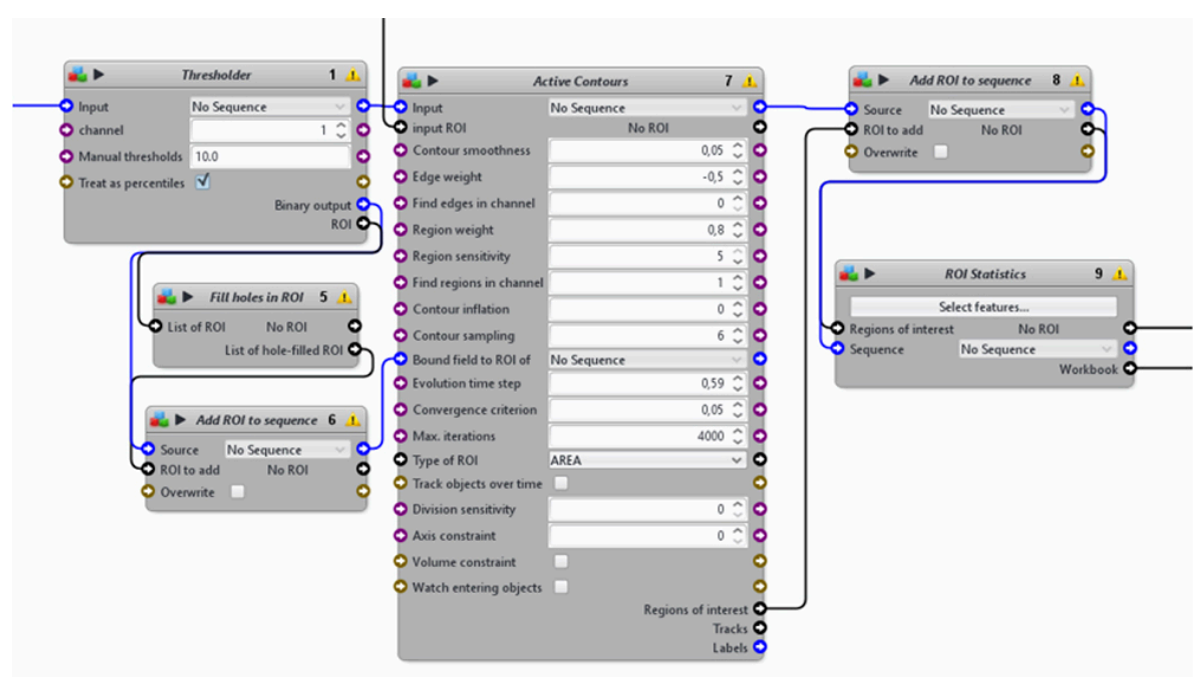

Figure 15. A second section from the automatic image-processing pipeline. From nuclei to single cells.

4. Identification of individual bacterium from either the FITC or TRITC channel to detect GFP- or dsRed-Salmonella, respectively (Figure 16).

a. Use 2 "Extract channel" blocks to extract the FITC and TRITC channels from image series.

b. Use 2 "Wavelet Spot Detector" blocks to identify individual bacterium within a certain size range.

c. Use 2 "add ROI to sequence" and 2 "ROI statistics" blocks to measure different features of the GFP- or dsRed-Salmonella (XY-position, size, etc.).

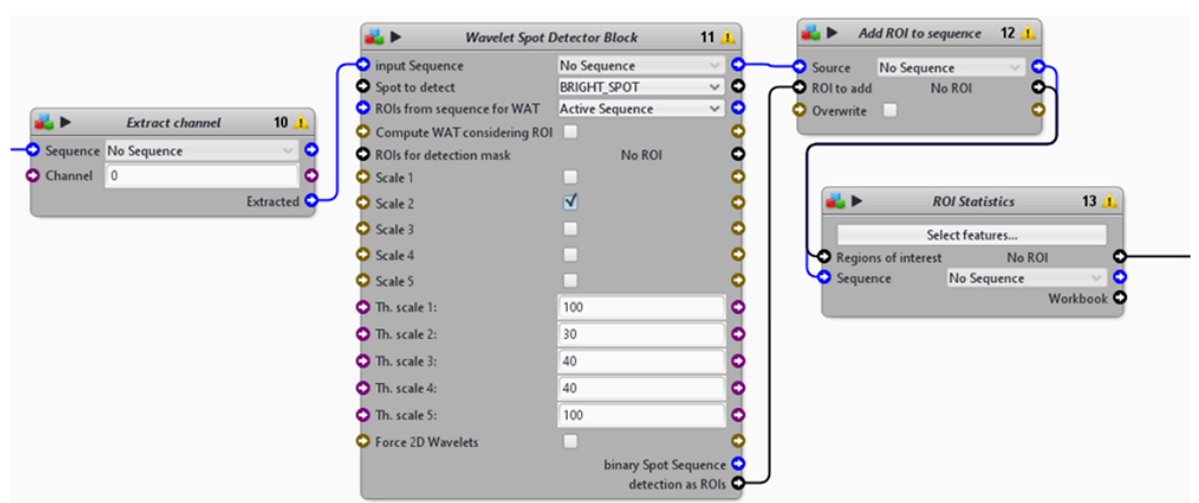

Figure 16. A third section from the automatic image-processing pipeline. From the FITC or TRITC channel extraction to the measurement of bacterial ROI.

5. More cellular features can be obtained by combining information from nuclei, cells, and bacteria. Icy provides the possibility to integrate a Javascript code to the pipeline inside a "Javascript" block, which enables the manipulation of ROls in a less rigid manner.

a. Use the "Javascript" block with the pre-integrated code from our pipeline to obtain the number of bacteria per cell and the number of neighboring cells (infected or not). 
b. The inputs of the block are the different lists of the detected ROIs, the measurements on these ROls, the number of image series extracted from the "Integer" block, and the name of the image set file extracted from the "File" block.

c. The output is a single spreadsheet (.txt) integrating all measurements done on individual cells from one experimental well.

B. Statistical analysis of the cell feature using $R$ code

1. From Icy output files to the final $R$ dataset

The data obtained with the automatic measurement of Icy are computed and analyzed with the open-source $\mathrm{R}$ software. All the lines in the grey boxes correspond to a code written in $\mathrm{R}$ language. These lines can be directly copied and pasted into the $R$ software ( $R$ Core Team, 2013).

The following part describes how an $\mathrm{R}$ dataset is prepared from the output file obtained with Icy. Each line of the table corresponds to one cell, referred latter as "cell of interest," and each column corresponds to the value of one of the measured variables.

Such a dataset contains all the variables measured from the analysis of images of one experimental well, plus some more elaborated variables obtained from the raw variables.

The following step (a) describes how the data are loaded from the variables measured with Icy. The step (b) describes how the cells on the border of the image are filtered. The steps (c) and (d) describe how more elaborated variables are added as new columns of the dataset. The step (e) describes how the final variables used for the modeling are selected. The step (f) describes how the data from each well are combined to create the final dataset that will be used in the modeling.

a. Load one of the .txt output files from the Icy analysis and check the number of variables.

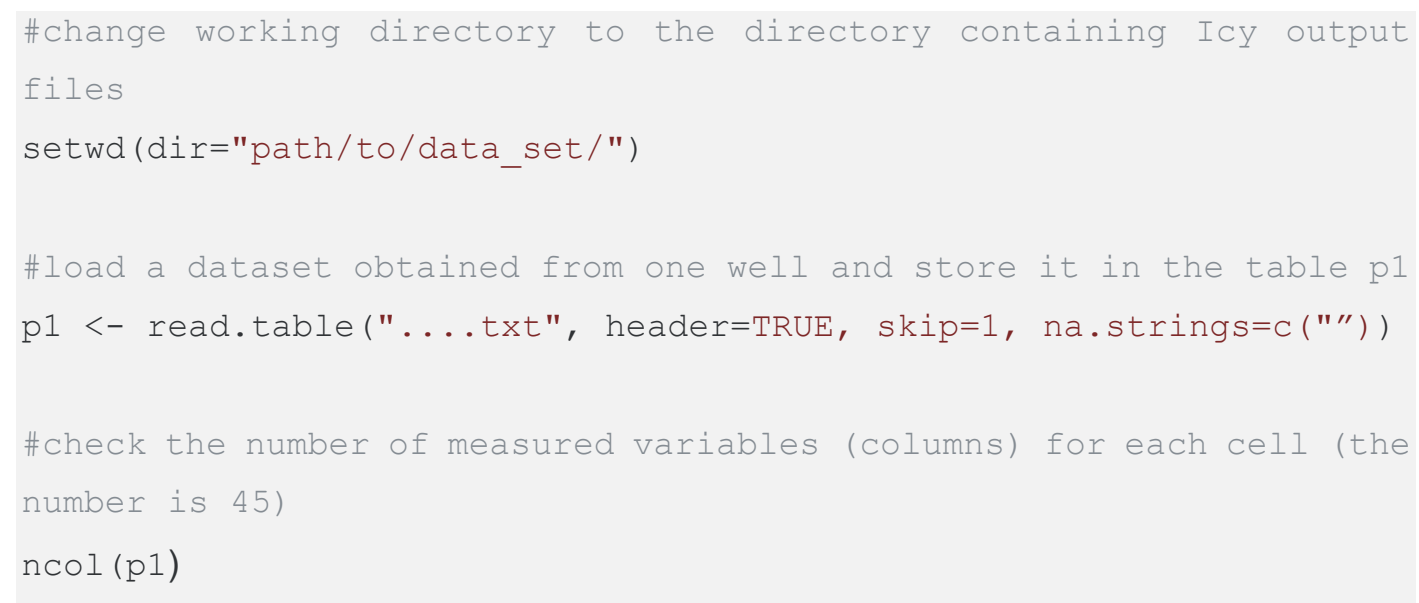

b. Add more variables to be used in the model such as square root of circularity, local cell density, and non-infected neighboring cells. Then, add manually the variable "delay", which is not included in the Icy output. 
\#add new columns to the table pl: they are used to store variables (square root of the circularity: "sqrt-circ", number of cells within $100 \mu \mathrm{m}$ of the given cell: "Cells_100_microns", number of noninfected neighboring cells: "neighbor_non_infl", delay between the first and the second infection: "delay")

$\mathrm{p} 1<-$ cbind $(\mathrm{p} 1,0,0,0,0)$

names (p1)[46:49] <- c("sqrt_circ", "Cells_100_microns", "neighbor_non_infl", "delay")

\#compute the square root of circularity for each cell using the formula: sqrt(4 x Cell Area / Cell Perimeter^2). The measured cell area is stored in the variable called "interior" and the cell perimeter is stored in the variable called "contour". The result is stored in the "sqrt_circ" column.

for (i in $1: \operatorname{nrow}(\mathrm{p} 1)) \quad\{$

p1\$sqrt_circ[i] <- sqrt $(4$ * pi * p1\$interior[i] / (p1\$contour[i] $\star \star 2$ ))

\}

\#compute the local cell density as the number of surrounding cells within the vicinity of $100 \mu \mathrm{m}$ of the cell of interest. The result is stored it in the "Cells_100_microns" column.

for ( $i$ in 1 nrow $(\mathrm{p} 1)) \quad\{\# i$ is the index of the cell of interest

\# set the number of cells within $100 \mu \mathrm{m}$ to minus 1 : the cell of interest is within its own 100 um vicinity

p1\$Cells_100_microns $[i]<-\quad-1$

\#subselect all the cells from the same image and store the data in a matrix $t$

$\mathrm{t}<-\mathrm{p} 1[(\mathrm{p} 1$ img $==$ p1\$img[i]), ]

for ( $j$ in 1 :nrow(t)) $\{\# j$ is the index of a cell in the same image

\#check for each cell of the image whether it is within the vicinity of $100 \mathrm{\mu m}$ (i.e. 312.5 pixels in our conditions) from the cell of interest by using the $X$ and $Y$ coordinates.

if $(\operatorname{sqrt}((\mathrm{p} 1 \$ \mathrm{X}[\mathrm{i}]-t \$ X[j]) \wedge 2+(\mathrm{p} 1 \$ Y[i]-t \$ Y[j]) \wedge 2)<$ $312.5) \quad\{$

\#add one to the counter if this is true

p1\$Cells_100_microns [i] <- p1\$Cells_100_microns[i] + 1

\}

\} 


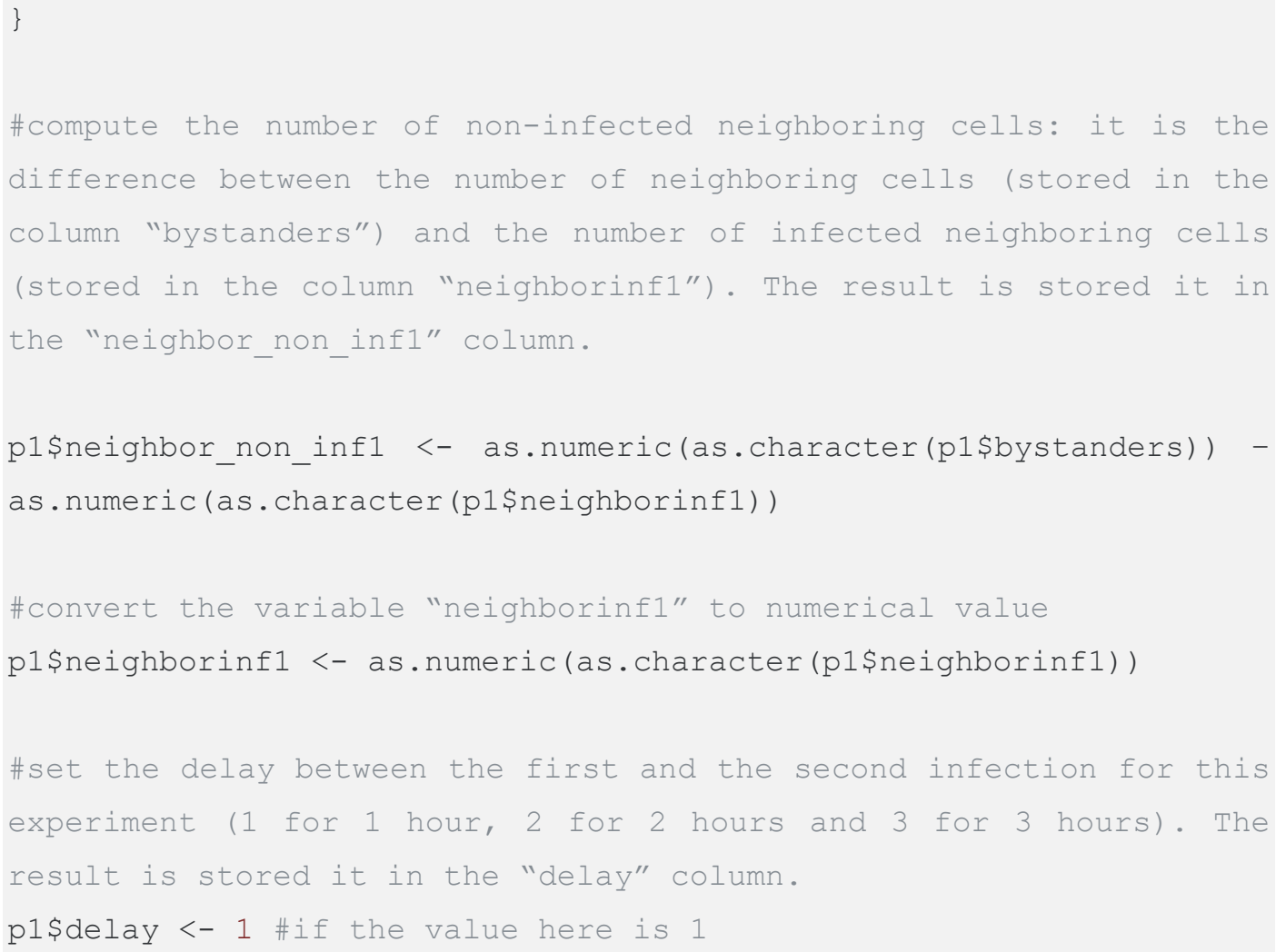

c. Cells on the border of images present a bias as not all the variables can be measured accurately for these cells. Filter them.

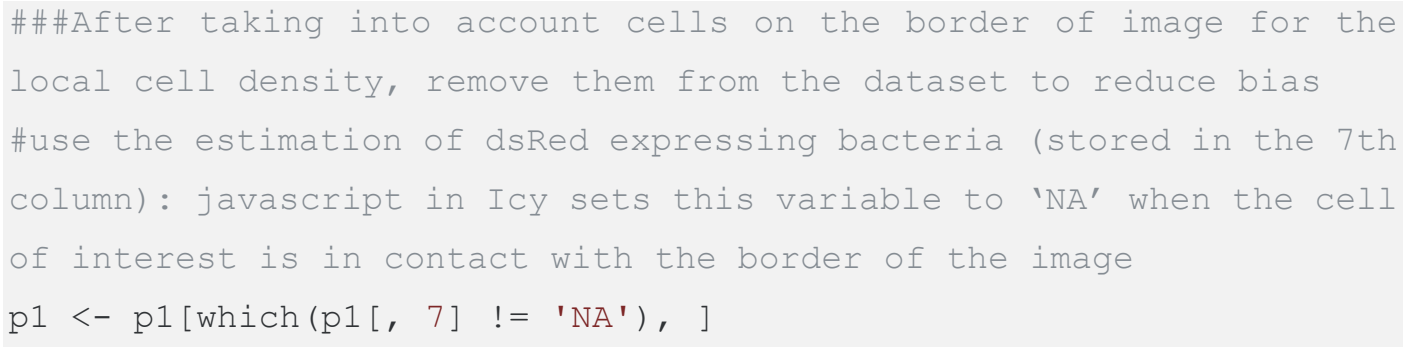

d. Add variables linked with the infection. Using estimates of the number of bacteria obtained in Icy, create variables representing the intensity of the first infection and the presence of the second one.

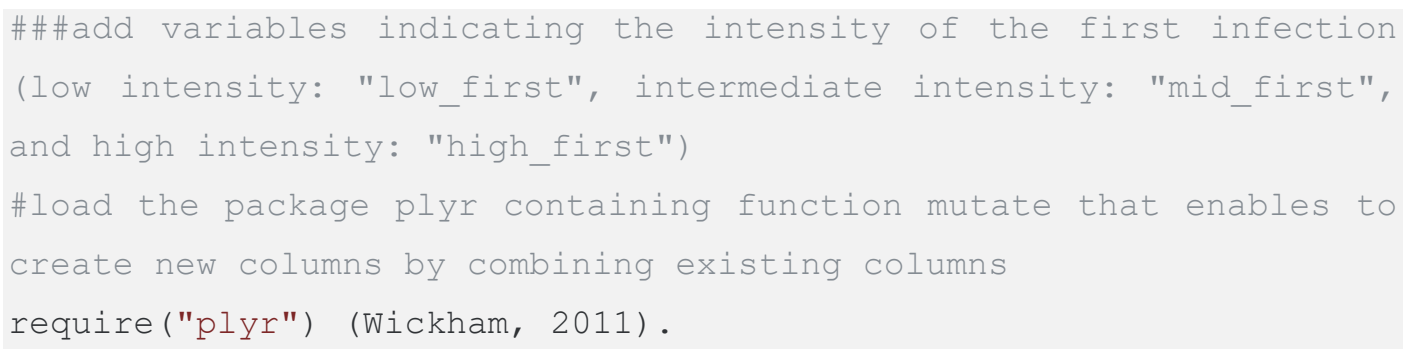




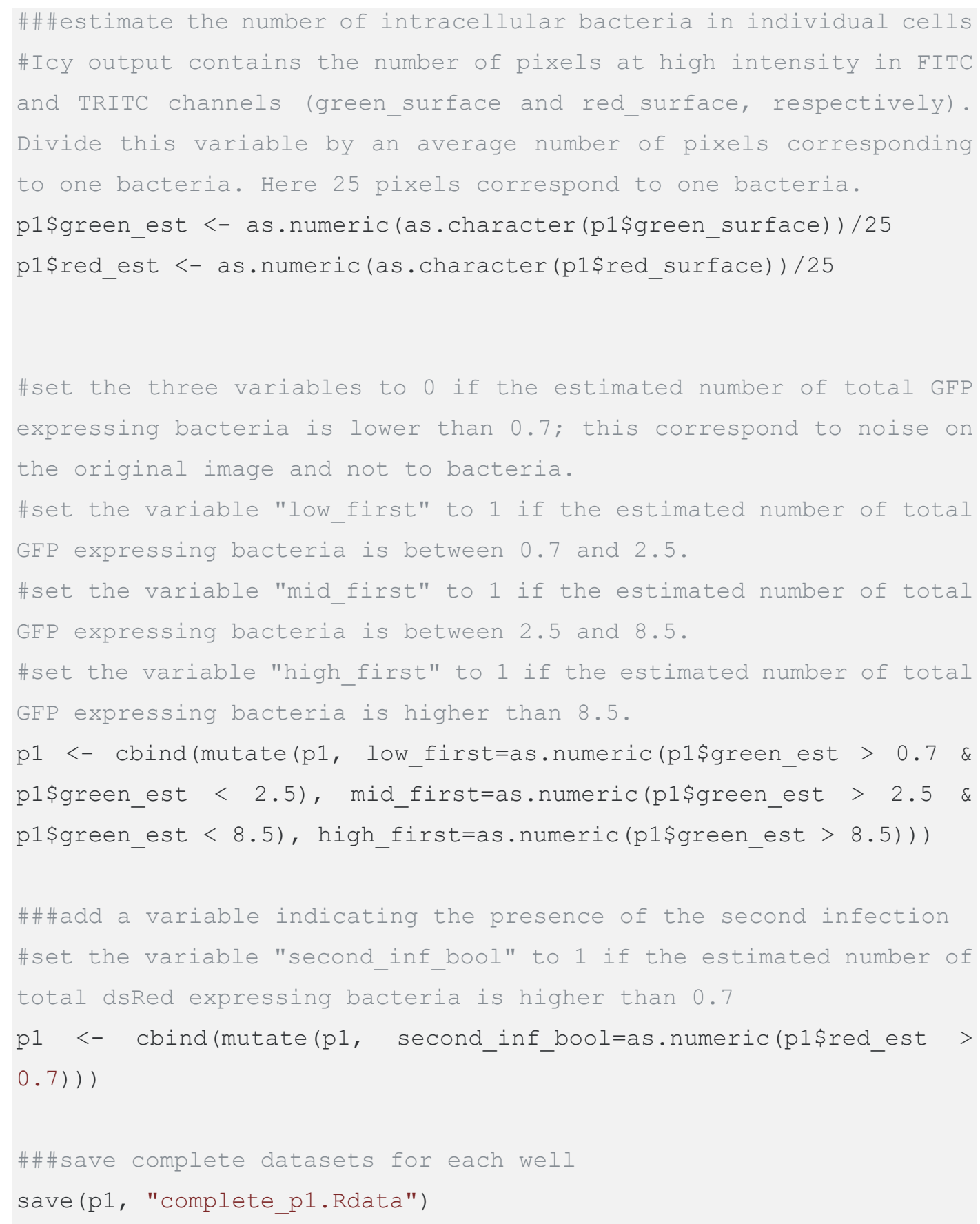

e. The table now contains over 50 variables. Select the variables to be used in the model (this can be adapted depending on the purpose of the analysis). Here, we select only 10 variables as described below:

i. second_inf_bool: boolean variable that takes the value 1 if the cell of interest contains bacteria from the second wave of infection, and 0 otherwise.

ii. low_first: boolean variable that takes the value 1 if the number of bacteria from the second infection is between 1 and 2 , and 0 otherwise.

iii. med_first: boolean variable that takes the value 1 if the number of bacteria from the second infection is between 3 and 8 , and 0 otherwise. 
iv. high_first: boolean variable that takes the value 1 if the number of bacteria from the second infection is 9 or more, and 0 otherwise.

v. cell_perim: continuous variable that takes the value of the perimeter of the cell of interest.

vi. sqrt_circularity: continuous variable that takes the value of the square root of the circularity of the cell of interest.

vii. neighbor_inf1: discrete variable that takes the value of the number of neighboring cells that were infected during the first wave of infection.

viii. neighbor_non_inf1: discrete variable that takes the value of the number of neighboring cells that were not infected during the first wave of infection.

ix. Cells_100_microns: discrete variable that takes the value of the number of cells within $100 \mu \mathrm{m}$ of the cell of interest.

$\mathrm{x}$. delay: categorical variable that takes the value of the delay (in hour) between the first and the second wave of infection.

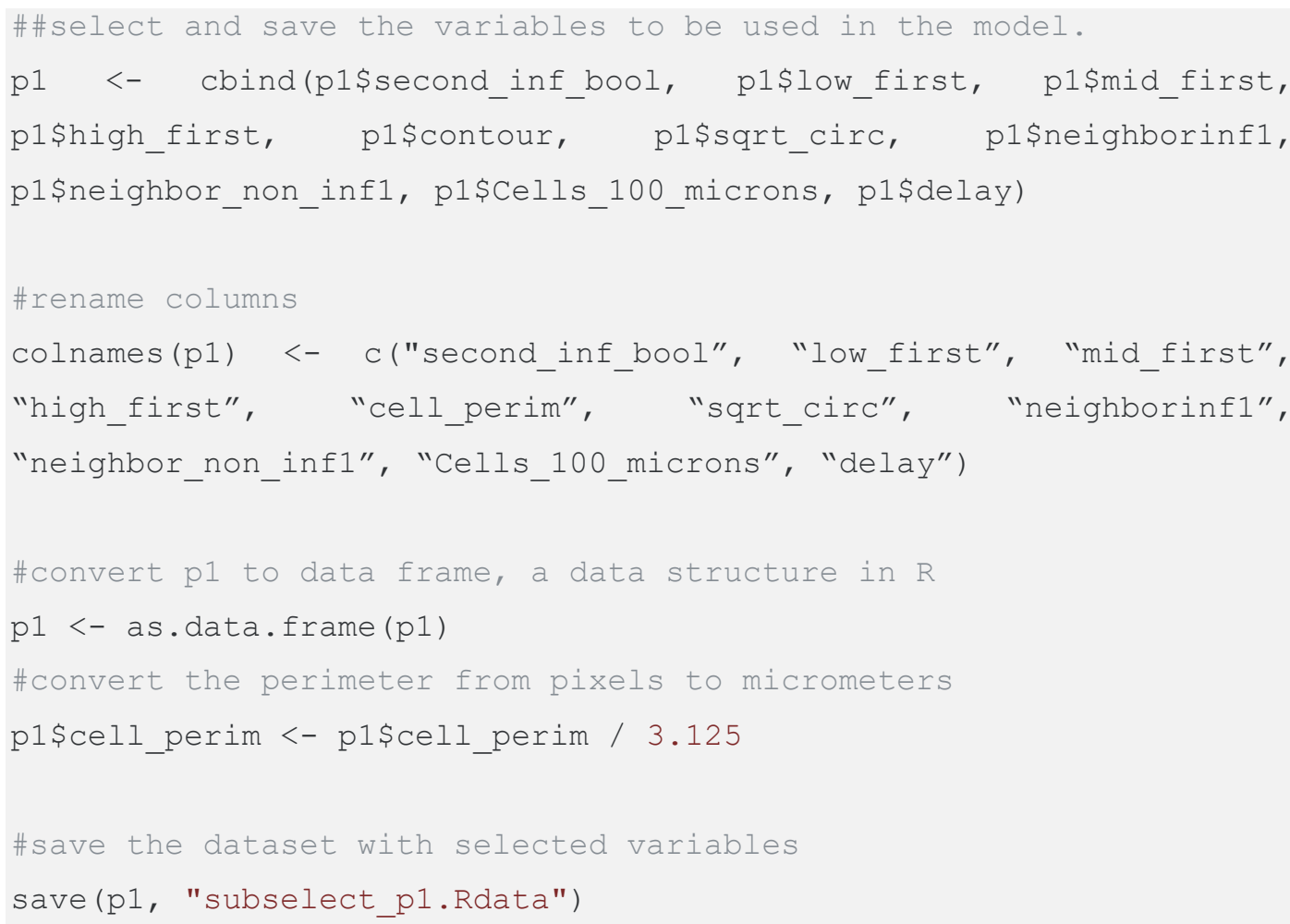

f. Combine the datasets acquired from single wells to create the final dataset used for further analysis.

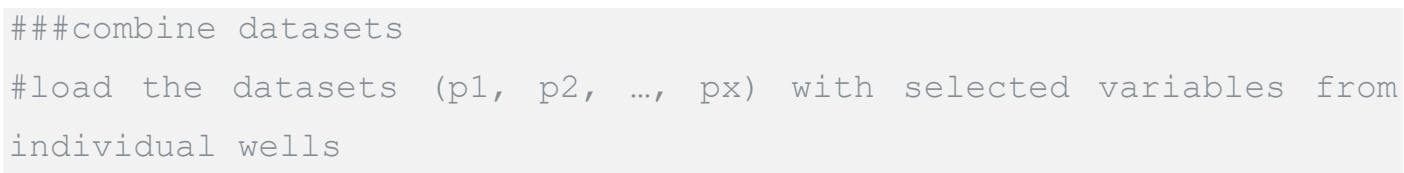




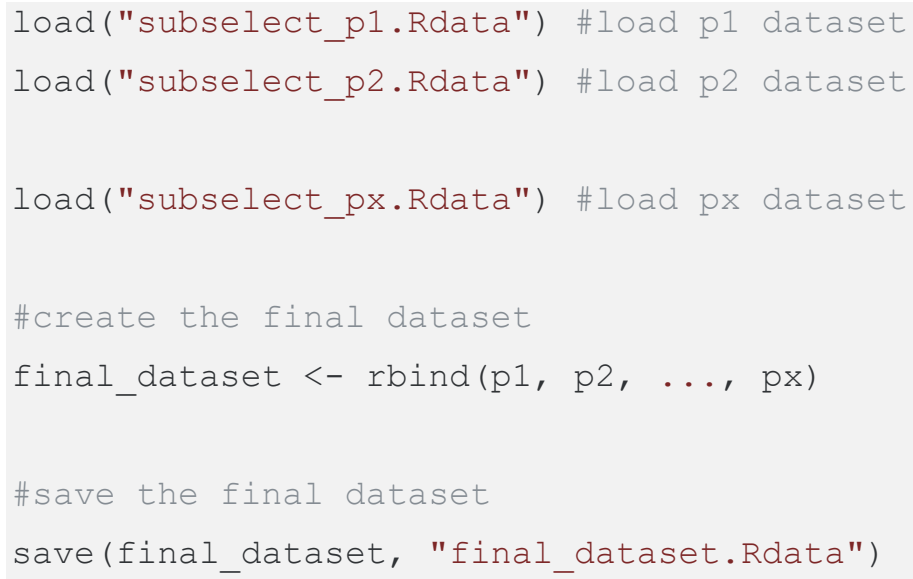

2. Visualizing the distribution of variables in infected and non-infected cells

Build plots comparing the distribution of a variable for infected and non-infected cells. These plots correspond to Figure 5A of our published article (Voznica et al., 2018). Here, we use the variable of infected neighboring cells ("neighinf1") as an example, but the script is adaptable to other variables.

a. Load the complete dataset containing the data from all wells.

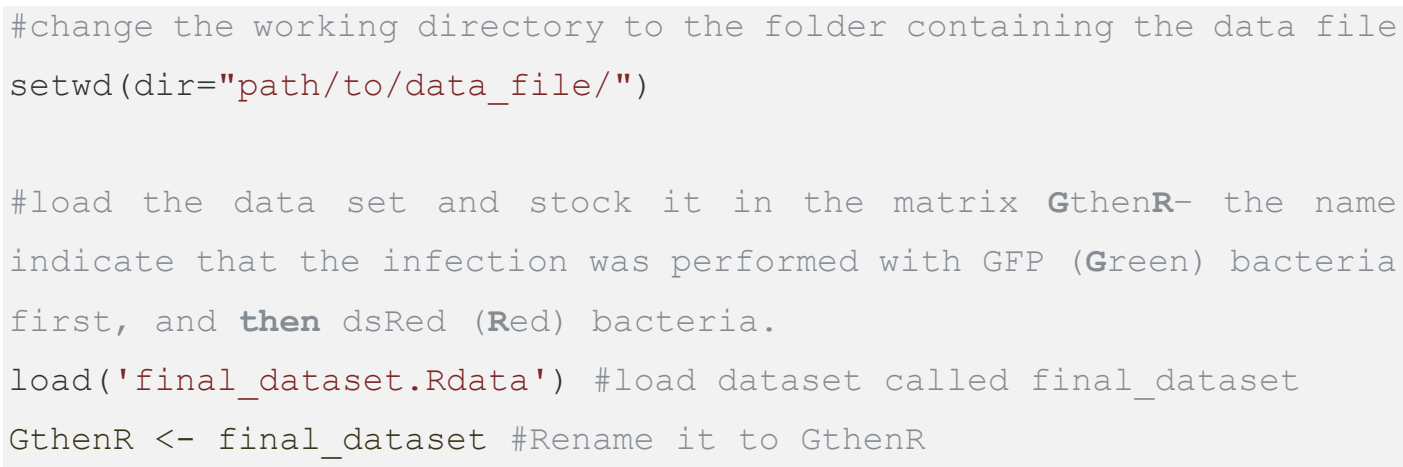

b. Separate the data into two groups. The first group corresponds to the cells infected during the second infection, called "infected cells". The second group corresponds to the cells not infected during the second infection, called "non-infected cells".

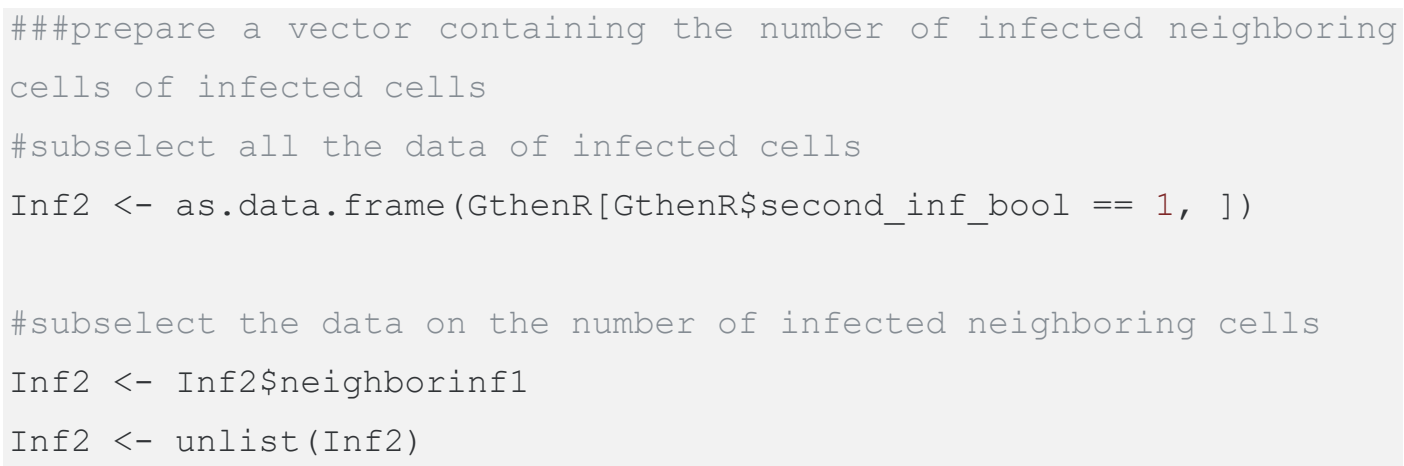




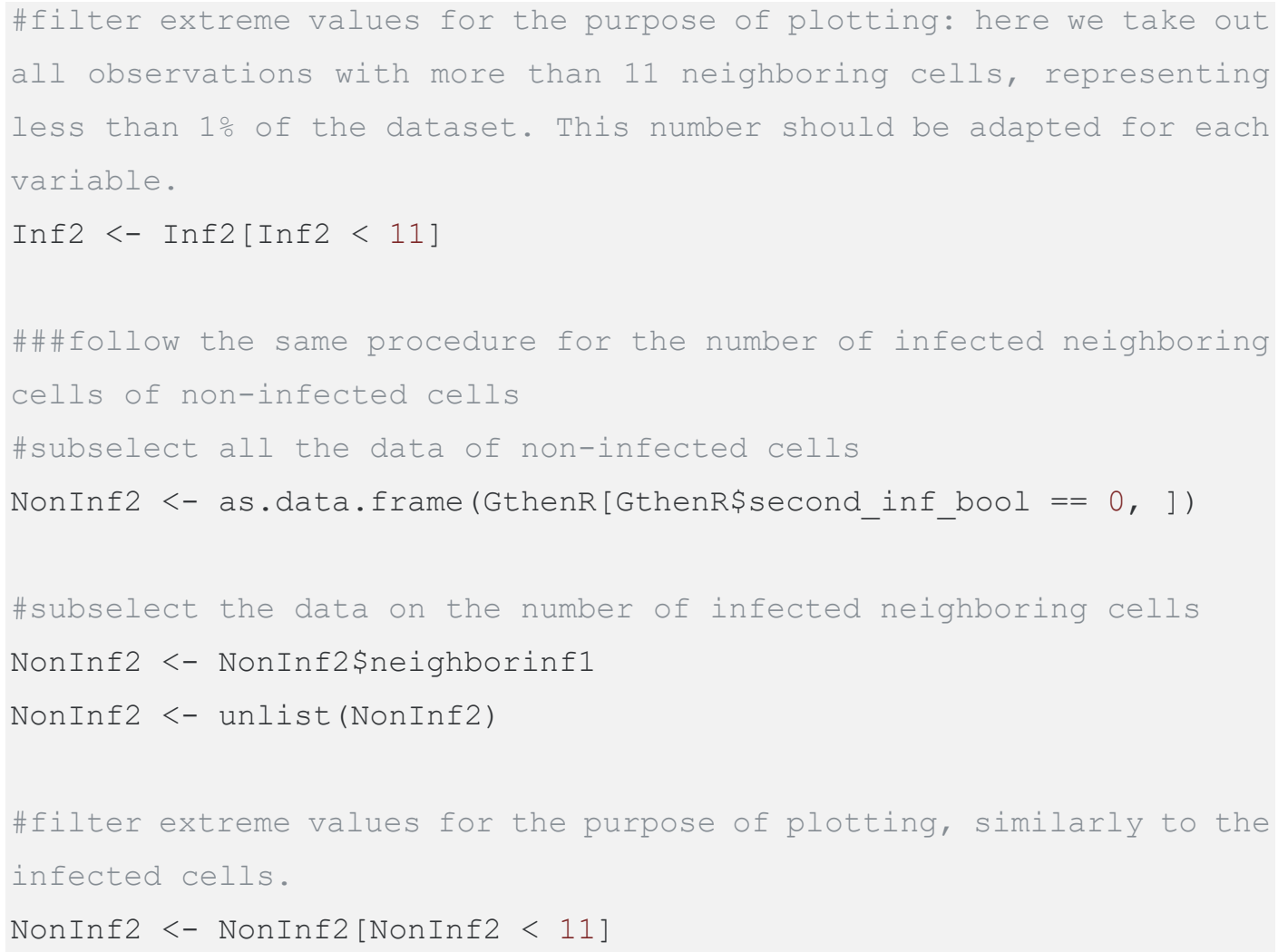

c. Prepare the histograms of the distribution of infected neighboring cells in infected and noninfected cells. The final plot is a density plot summing to $100 \%$.

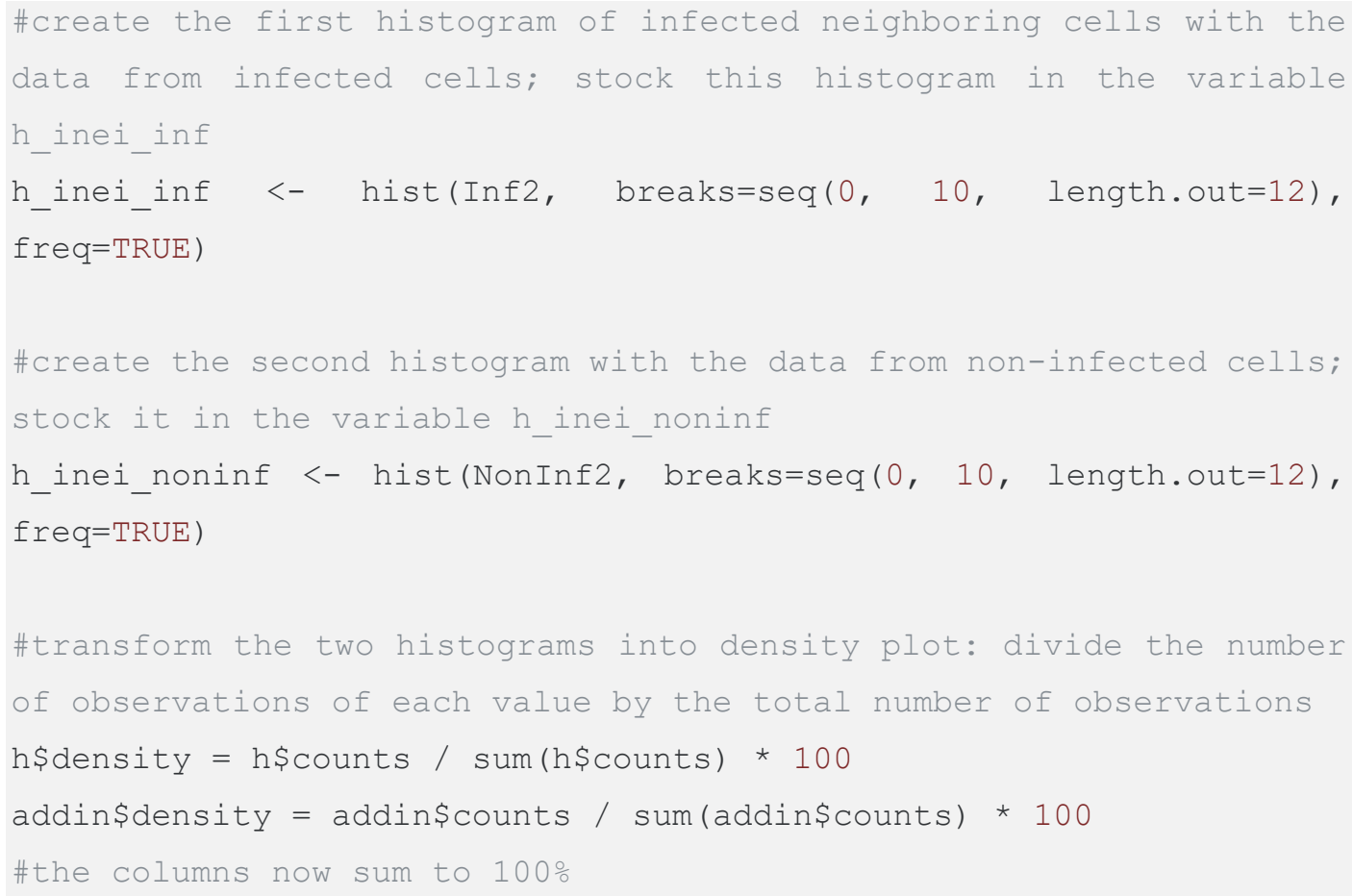

d. Plot the distribution to obtain a figure similar to Figure 17. 


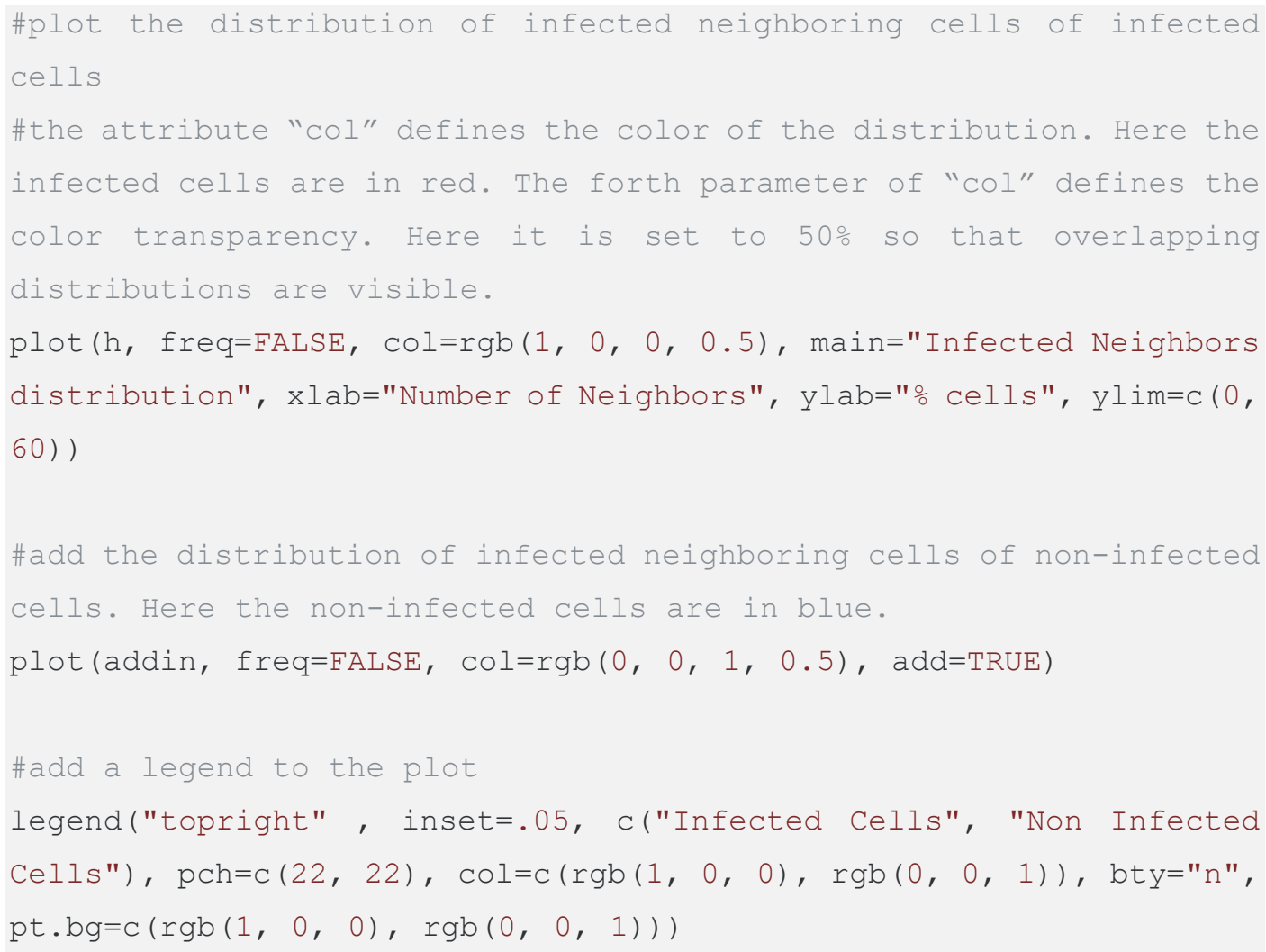

Infected Neighbors distribution

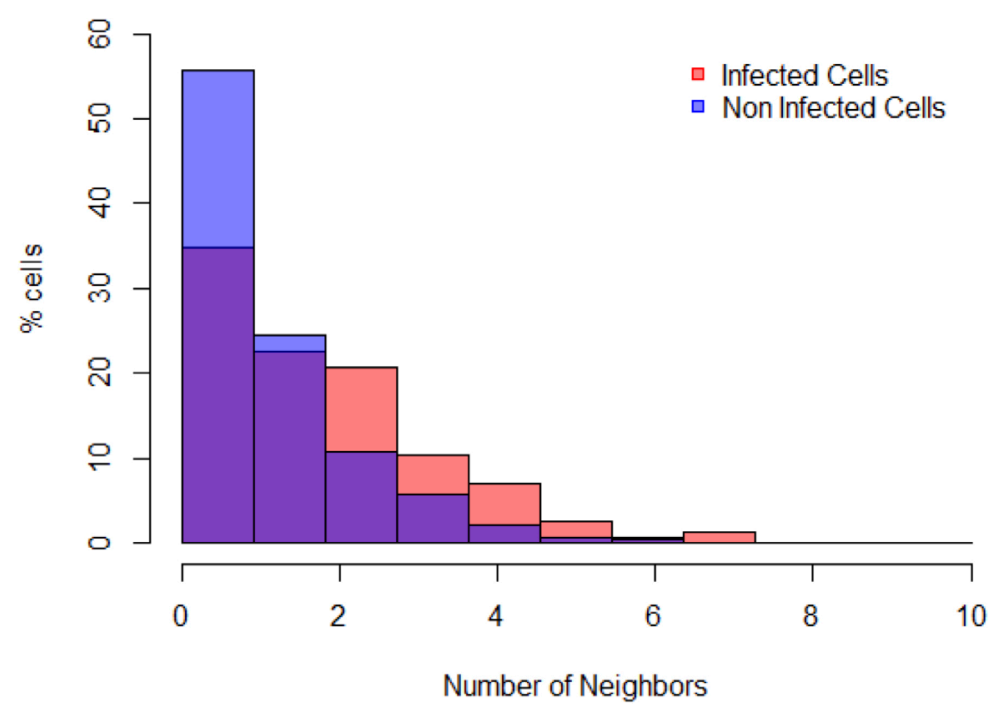

Figure 17. Visualization of the distribution of the number of infected neighboring cells for infected cells (in red) and non-infected cells (in blue)

3. Testing the involvement of cell features in the cell vulnerability to Salmonella infection In order to test the involvement of different cell features in the cell vulnerability to Salmonella infection, build a trained model to predict the infected cells from their features, and test the accuracy (i.e., likelihood) of such model. Then, test a new model missing one of the parameters. 
By subtracting the likelihood between both models, quantify the improvement of the infection prediction and conclude on the involvement of the cell feature studied in the cell vulnerability. These quantifications correspond to Figure 5B of our published article (Voznica et al., 2018).

a. Load the complete dataset (see Note 12), and convert 2 of the variables to categorical variables.

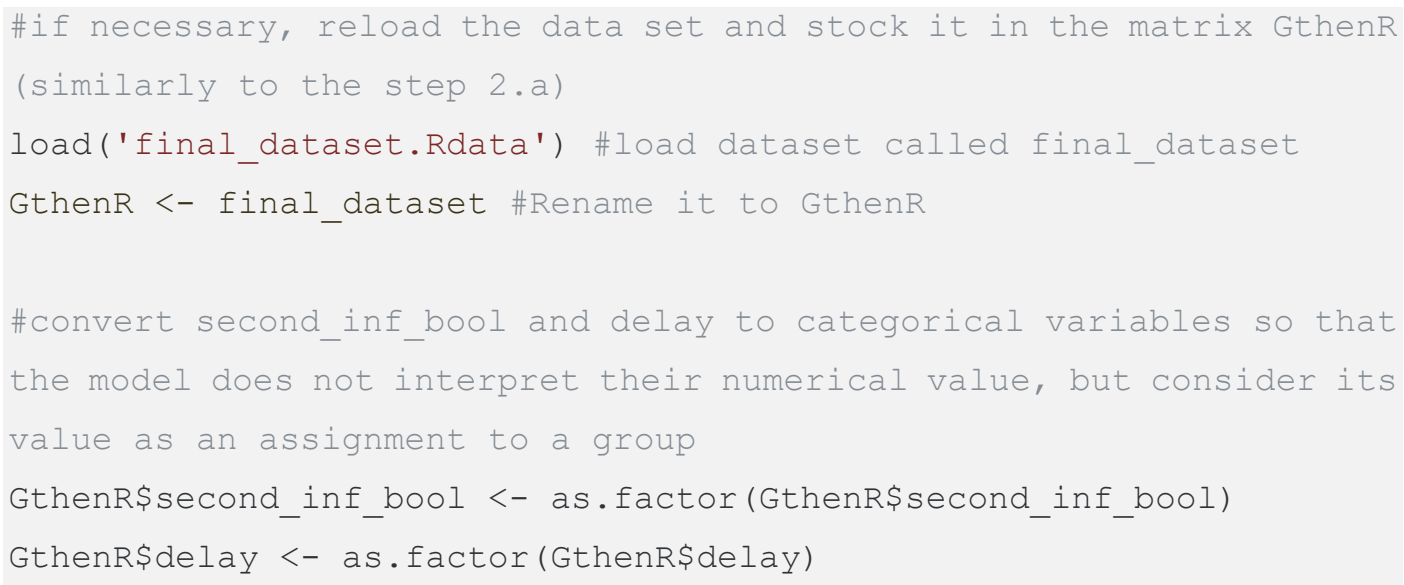

b. Partition the data into training and testing datasets. Create two tables containing indexes for data partitioning. One table for the training dataset containing $9 / 10^{\text {th }}$ of the total data, the other one for the testing dataset containing $1 / 10^{\text {th }}$ of the total data. The repartition of the data between the training and the testing dataset is done with 100 different cuts.

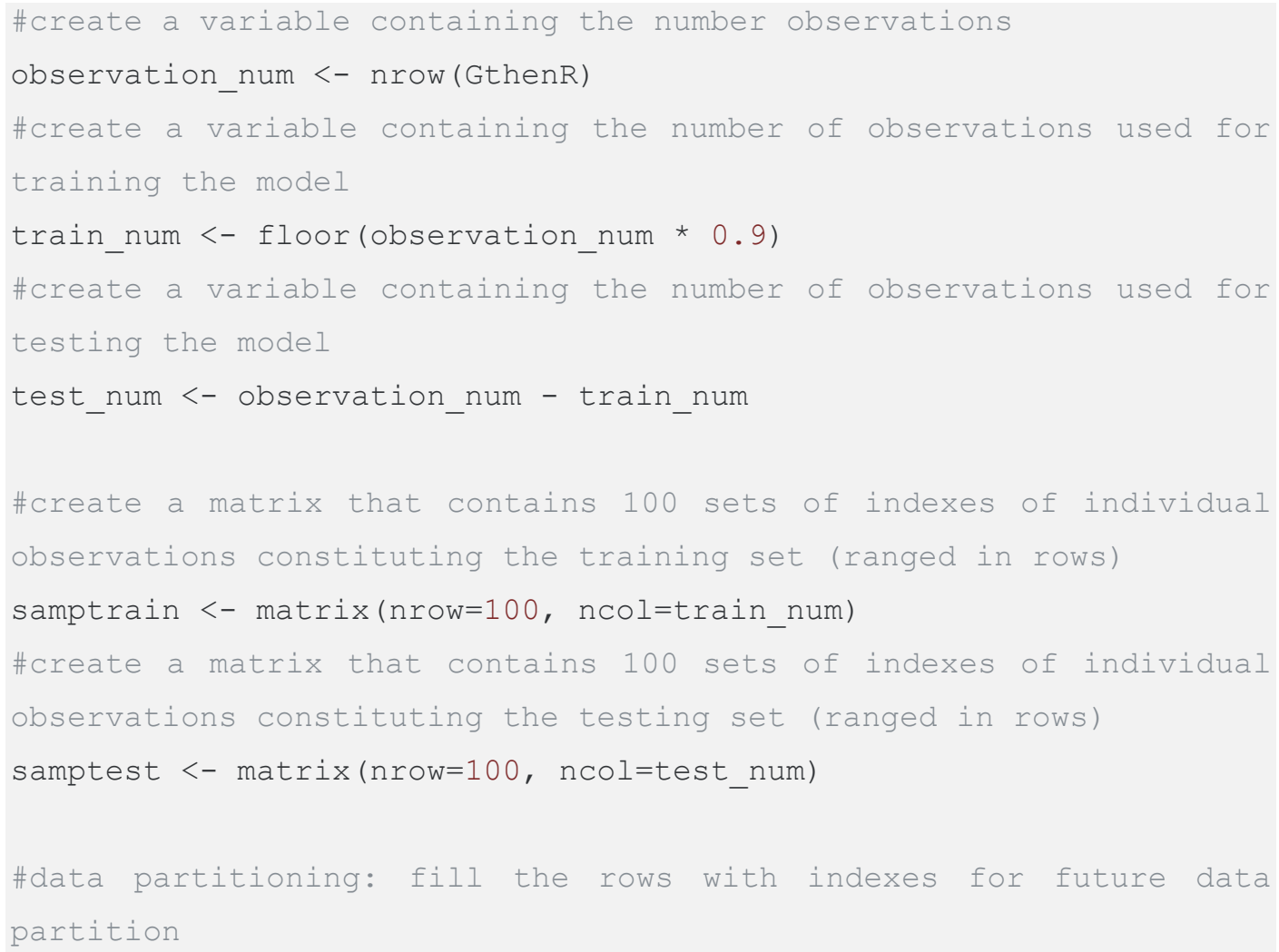




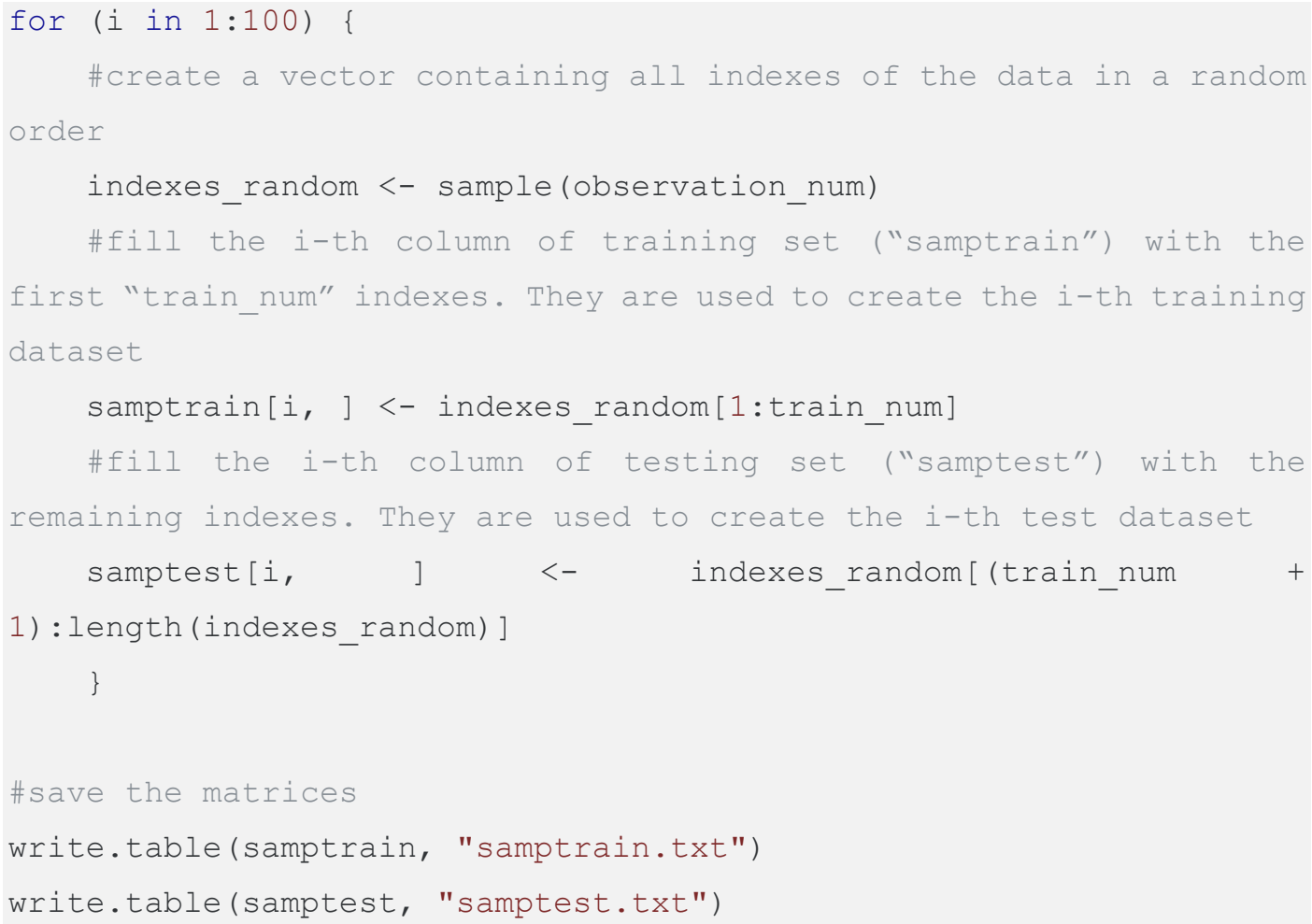

c. Evaluate predicting capacities for the complete and partial models missing one of the variables.

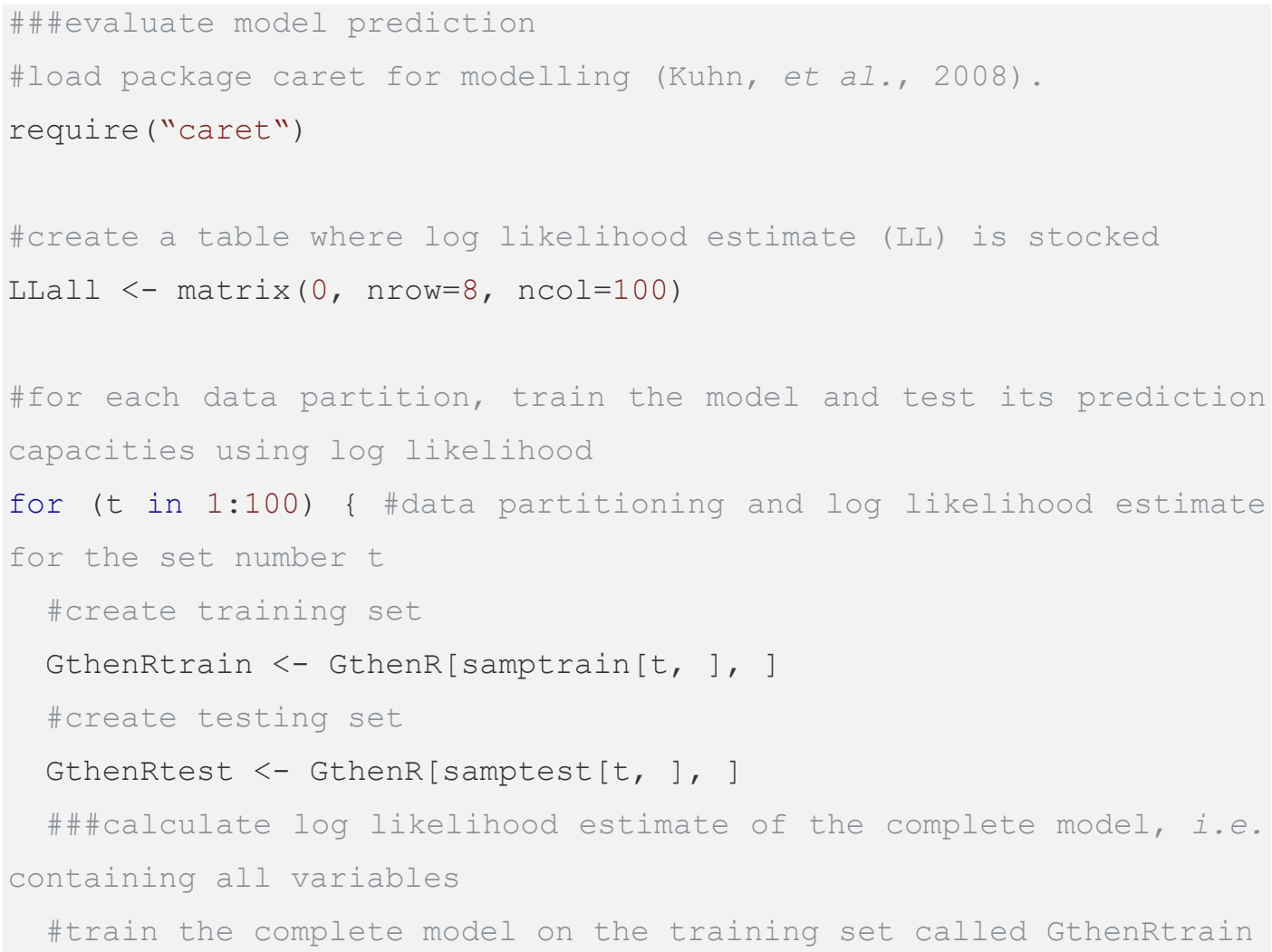




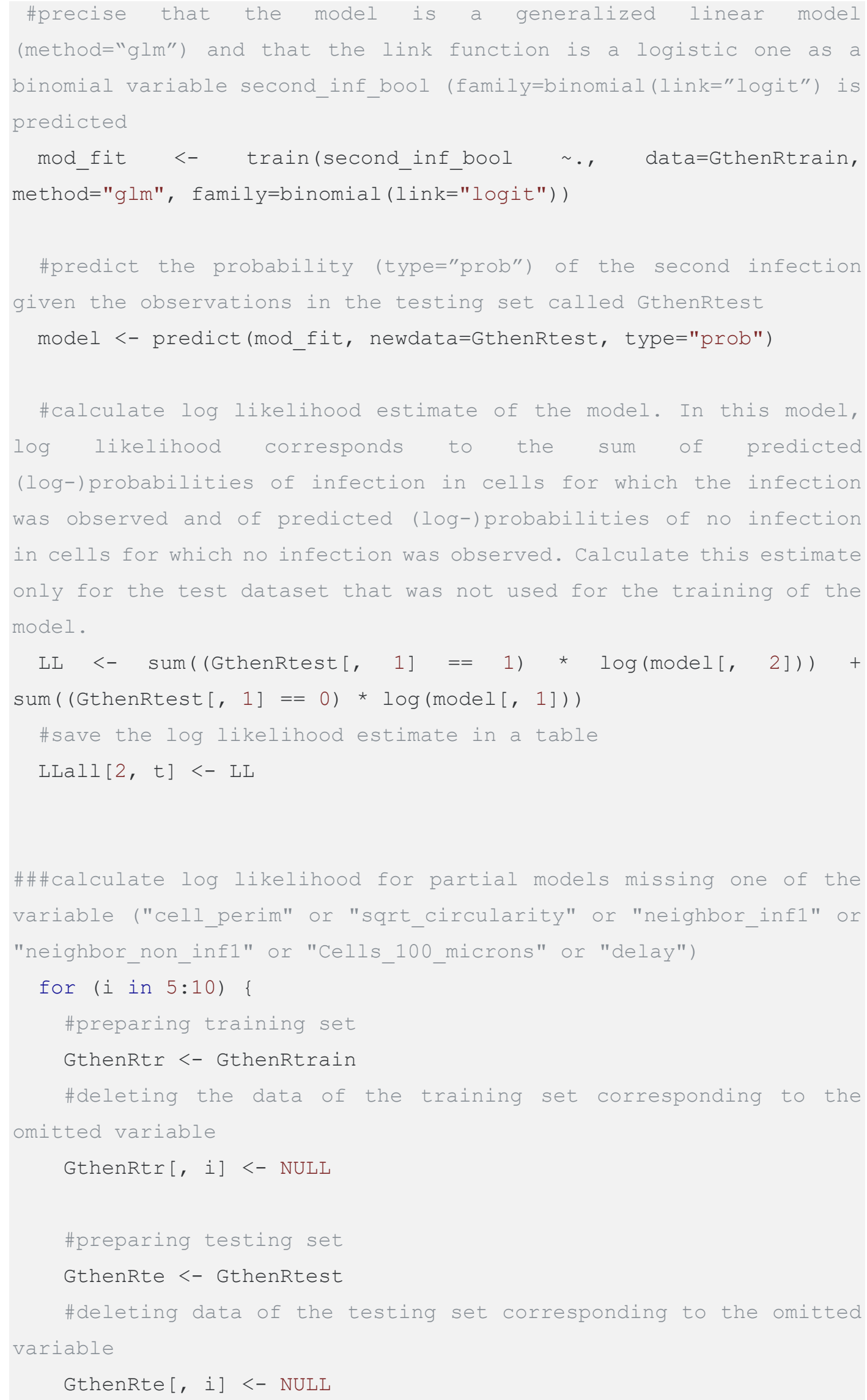




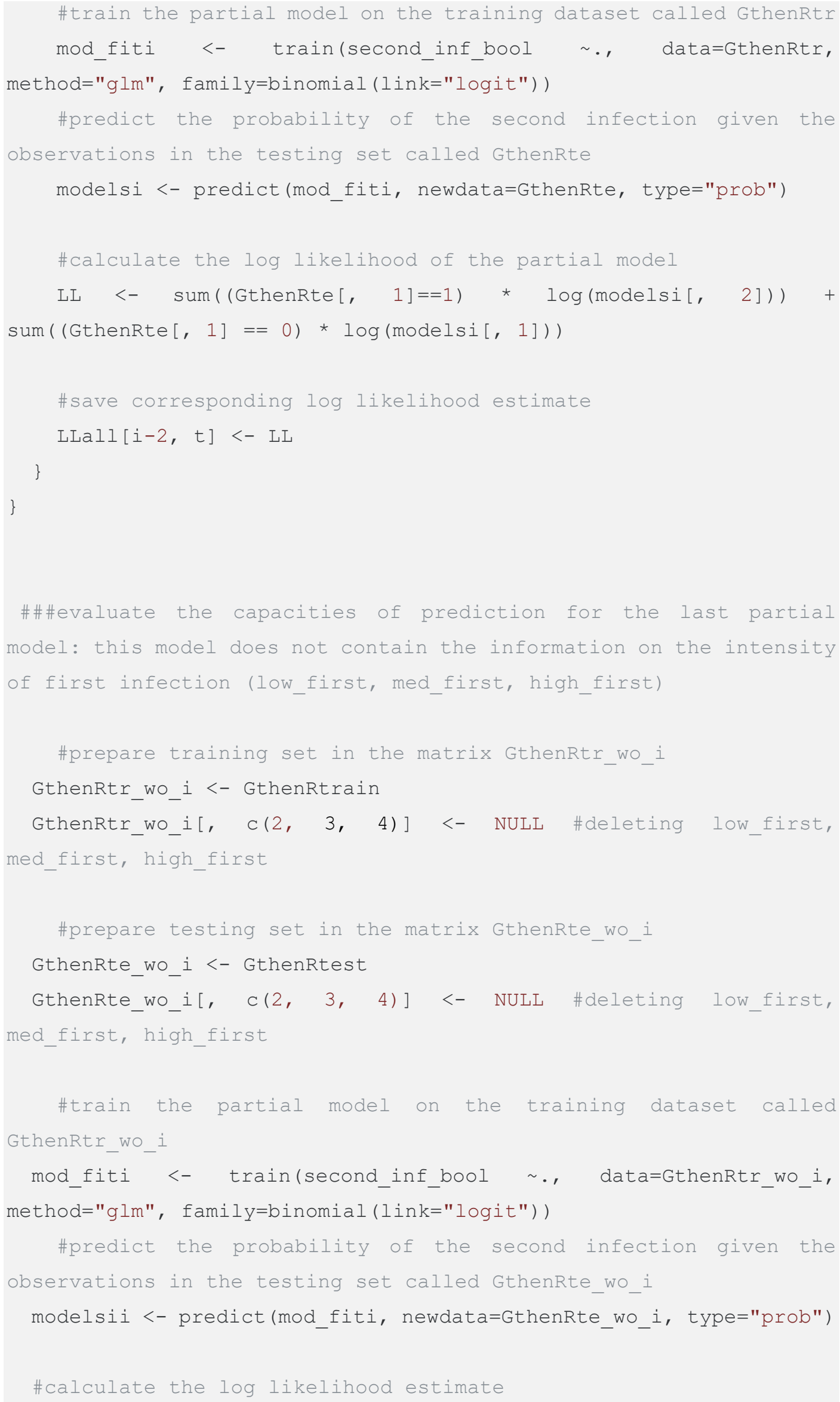




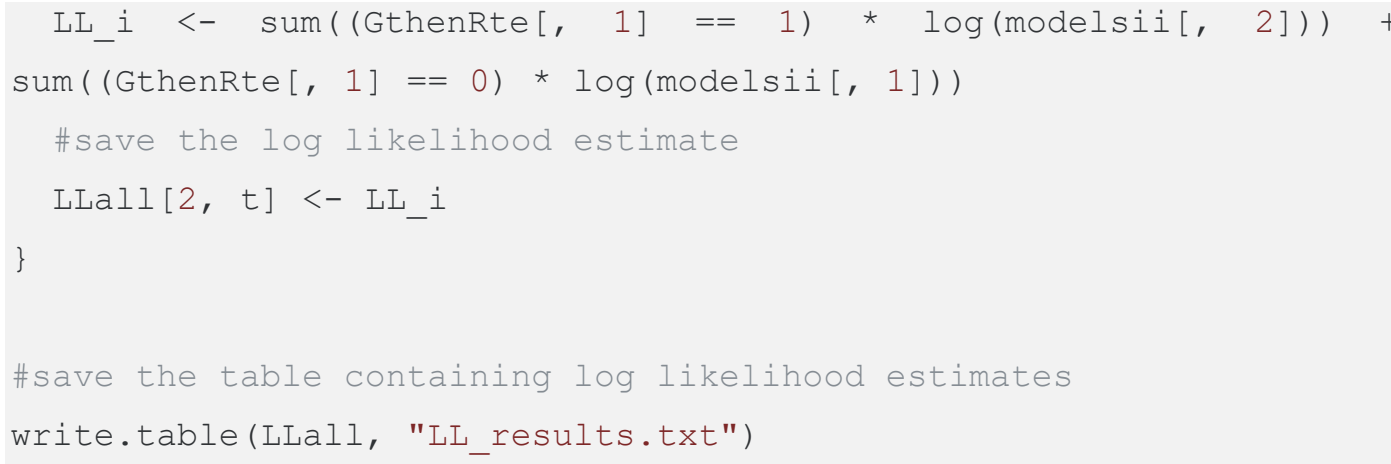

d. Plot the data from the LL_results.txt file obtained using GraphPad Prism (Figure 18)

e. Perform a statistical paired $t$-test between the complete and the partial model.

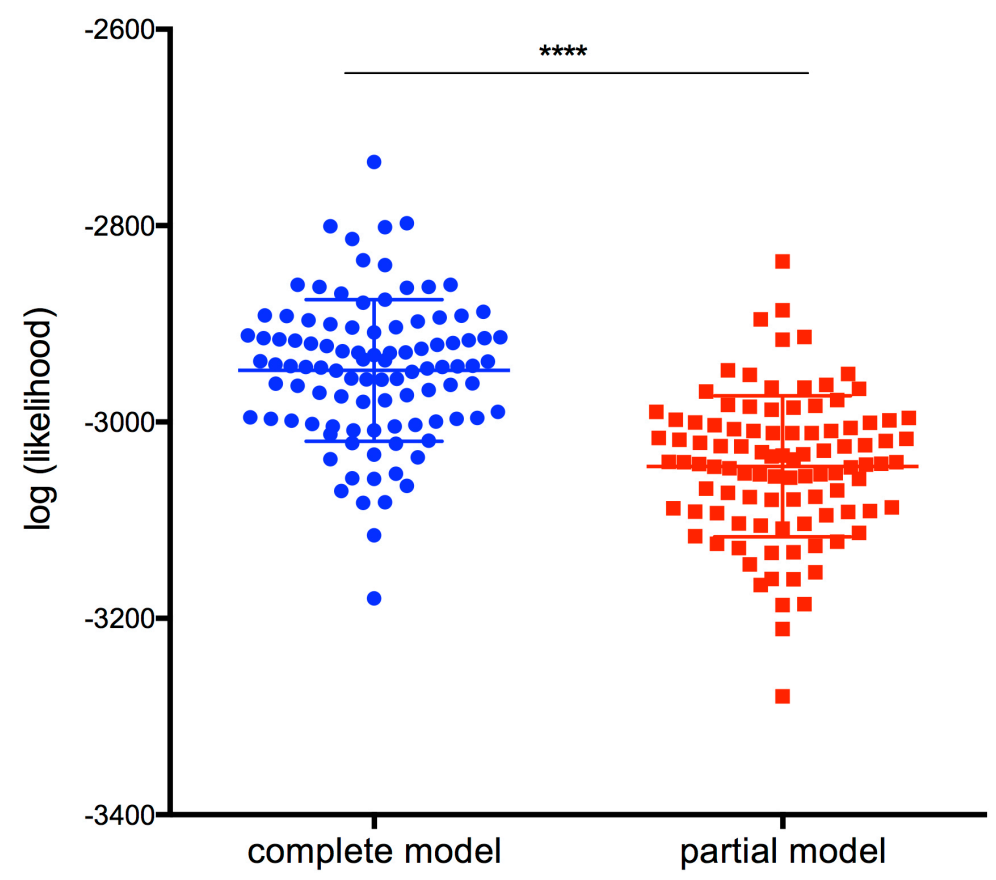

Figure 18. Comparison of the log (likelihood) of the complete model versus the partial model, lacking the information on the intensity of the first infection ${ }^{* * * *}, P$-value < 0. 0001)

\section{$\underline{\text { Notes }}$}

1. The colonies display a "red" or "green" color.

2. The inclination of the tube is important to aerate the samples.

3. Remember to equilibrate the centrifuge properly.

4. The adjacent wells at the periphery of the designed map should be filled with $100 \mu \mathrm{l}$ of warm DPBS to increase the reproducibility or the infection between each well (see Figure 2).

5. The inclination of the tube is important to aerate the samples. 
6. Do not vortex any tube containing Salmonella, as it would break the flagella and drastically decrease the efficiency of infection.

7. The decrease of the gentamicin concentration after $1 \mathrm{~h}$ of incubation helps to prevent the incorporation of gentamicin into the cells.

8. The plate can be kept at $4{ }^{\circ} \mathrm{C}$ for a few days before acquisition.

9. The parameters that need to be adapted between experiments are in the blocks "HK-means", "Active Contours" and "Wavelet Spot Detector".

10. The number on the top right corner of each block indicates the order in which the blocks are executed in the pipeline.

11. The proper calibration of the "Active Contours" block parameters determines the success of image analysis. They should be adapted by trial and error. A "Display" block can be used to follow the segmentation process visually.

12. It is necessary to reload the dataset only if the Steps B2 and B3 of the analysis (Data analysis section) are not done on the raw.

\section{$\underline{\text { Recipes }}$}

1. Heat inactivation of the Fetal Bovine Serum
a. Aliquot the serum into $50 \mathrm{ml}$ labeled Falcon tubes
b. Heat inactivate the aliquots in the water bath for $30 \mathrm{~min}$ at $56{ }^{\circ} \mathrm{C}$
c. Cool down at RT and store at $-20^{\circ} \mathrm{C}$ for up to several weeks

2. Salmonella transformation

a. Dilute $500 \mu \mathrm{l}$ of an overnight culture of SL1344 in $50 \mathrm{ml}$ of LB in a $250 \mathrm{ml}$ Erlenmeyer flask

b. Incubate the subcultures for $3 \mathrm{~h}$ in a $45^{\circ}$-tilted rack of an incubator at $37^{\circ} \mathrm{C}$ with an orbital shaker at $220 \mathrm{rpm}$

c. Transfer the subculture into a cold $\left(4^{\circ} \mathrm{C}\right) 50 \mathrm{ml}$ Falcon ${ }^{\circledR}$ tube

d. Centrifuge at $3,200 \times \mathrm{g}$ for $10 \mathrm{~min}$ at $4{ }^{\circ} \mathrm{C}$ using Centrifuge $5810 / 5810 \mathrm{R}$

e. Discard the supernatant and resuspend the pellet in $20 \mathrm{ml}$ of ice-cold distilled water

f. Repeat steps $d$ and $e$

g. Discard the supernatant and resuspend the pellet in $100 \mu \mathrm{l}$ of distilled water

h. Add $2 \mu \mathrm{l}$ of DNA (here, pGG2 or pM965 plasmids)

i. Transfer the bacteria with DNA into a cold $\left(4^{\circ} \mathrm{C}\right)$ electroporation cuvette

j. Incubate for $10 \mathrm{~min}$ on ice

k. Electroporate the bacteria using the Gene Pulser Electroporation Systems programmed for E. coli (program number 4)

I. Add $1 \mathrm{ml}$ of LB to the cuvette and transfer the bacteria to an Eppendorf tube

$\mathrm{m}$. Incubate for $1 \mathrm{~h}$ in an incubator at $37^{\circ} \mathrm{C}$ with an orbital shaker at $220 \mathrm{rpm}$

n. Spread $20 \mu \mathrm{l}$ of the culture on a petri dish containing appropriate antibiotics corresponding to the resistance cassette encoded on the plasmid (here, ampicillin) 
o. Incubate at $37^{\circ} \mathrm{C}$ overnight

p. Select individual colonies and grow overnight in LB supplemented with the appropriate antibiotics (here, ampicillin at $100 \mu \mathrm{g} / \mathrm{ml}$ )

q. Make glycerol stock and store at $-80^{\circ} \mathrm{C}$

3. Lysogeny Broth (LB) medium supplemented with $0.3 \mathrm{M} \mathrm{NaCl}(1 \mathrm{~L})$
a. Weigh $10 \mathrm{~g}$ of Tryptone (BD)
b. Weigh $5 \mathrm{~g}$ Yeast Extract (BD)
c. Weigh $17.5 \mathrm{~g} \mathrm{NaCl}$ (Sigma-Aldrich)
d. Volume up to $1 \mathrm{~L}$ of solution with distilled water
e. Adjust the $\mathrm{pH}$ to 7.4
f. Autoclave for $20 \mathrm{~min}$ at $120^{\circ} \mathrm{C}$
g. Store at RT

4. LB agar (1 L)
a. Weigh $10 \mathrm{~g}$ Tryptone (BD)
b. Weigh $5 \mathrm{~g}$ Yeast Extract (BD)
c. Weigh $5 \mathrm{~g} \mathrm{NaCl}$ (Sigma-Aldrich)
d. Agar Solidifying Agent (BD)
e. Volume up to $1 \mathrm{~L}$ of solution with distilled water
f. Adjust the $\mathrm{pH}$ to 7.4
g. Autoclave for $20 \mathrm{~min}$ at $120^{\circ} \mathrm{C}$
h. Store at RT

5. LB agar plate containing ampicillin at $100 \mu \mathrm{g} / \mathrm{ml}$
a. Melt the LB agar in a double boiler for $13 \mathrm{~min}$ in the microwave at $700 \mathrm{~W}$
b. Wait $30 \mathrm{~min}$ at RT until the medium cools down; add ampicillin at $100 \mu \mathrm{g} / \mathrm{ml}$ and swirl the LB agar solution to ensure the ampicillin is well mixed Note: It should be comfortable to touch with an ungloved hand, but still fairly hot.
c. Pour agar into round Petri plates
d. Allow plates to sit overnight at RT and store at $4{ }^{\circ} \mathrm{C}$

6. EM medium $20 \times(1 \mathrm{~L})$
a. Weigh $140.3 \mathrm{~g} \mathrm{NaCl}$ (Sigma-Aldrich)
b. Weigh $10.4 \mathrm{~g} \mathrm{KCl}$ (Thermo Fisher Scientific)
c. Weigh $4 \mathrm{~g} \mathrm{CaCl}_{2}$ (Sigma-Aldrich)
d. Weigh $1.52 \mathrm{~g} \mathrm{MgCl}_{2}$ (Sigma-Aldrich)
e. Weigh $18 \mathrm{~g}$ glucose (Sigma-Aldrich)
f. Weigh $119.1 \mathrm{~g} \mathrm{HEPES}$ (Sigma-Aldrich)
g. Volume up to $1 \mathrm{~L}$ of solution with distilled water
h. Adjust the $\mathrm{pH}$ to 7.4
i. Autoclave for $30 \mathrm{~min}$ at $110^{\circ} \mathrm{C}$
j. Store at $4{ }^{\circ} \mathrm{C}$ 
7. EM medium $1 \mathrm{x}$

For $1 \mathrm{~L}$ of EM medium 1x, dilute $50 \mathrm{ml}$ of EM medium 20x in $950 \mathrm{ml}$ of distilled water

\section{Acknowledgments}

V.S. was supported by a Ph.D. fellowship from the University Paris Diderot allocated by the ENS Cachan, Universite Paris-Saclay; and a grant from the FRM. J.E. is a member of the LabEx consortia IBEID and Milieulnterieur. J.E. also acknowledges support from the ANR (grant StopBugEntry and AutoHostPath) and the ERC (CoG EndoSubvert).

This protocol was originally performed within the article entitled "Identifying parameters of host cell vulnerability during Salmonella infection by quantitative image analysis and modelling" (Voznica et al., 2018).

\section{Competing interests}

Authors have no conflicts of interest or competing interests to declare.

\section{References}

1. de Chaumont, F., Dallongeville, S., Chenouard, N., Herve, N., Pop, S., Provoost, T., MeasYedid, V., Pankajakshan, P., Lecomte, T., Le Montagner, Y., Lagache, T., Dufour, A. and OlivoMarin, J. C. (2012). Icy: an open bioimage informatics platform for extended reproducible research. Nat Methods 9(7): 690-696.

2. Frechin, M., Stoeger, T., Daetwyler, S., Gehin, C., Battich, N., Damm, E. M., Stergiou, L., Riezman, H. and Pelkmans, L. (2015). Cell-intrinsic adaptation of lipid composition to local crowding drives social behaviour. Nature 523(7558): 88-91.

3. Fredlund, J., Santos, J. C., Stevenin, V., Weiner, A., Latour-Lambert, P., Rechav, K., Mallet, A., Krijnse-Locker, J., Elbaum, M. and Enninga, J. (2018). The entry of Salmonella in a distinct tight compartment revealed at high temporal and ultrastructural resolution. Cell Microbiol 20(4).

4. Haraga, A., Ohlson, M. B. and Miller, S. I. (2008). Salmonellae interplay with host cells. Nat Rev Microbiol 6(1): 53-66.

5. Knodler, L. A. (2015). Salmonella enterica: Living a double life in epithelial cells. Curr Opin Microbiol 23: 23-31.

6. Kuhn, M. (2008). Building predictive models in R using the caret package. J Stat Softw 28(5): $1-26$.

7. LaRock, D. L., Chaudhary, A. and Miller, S. I. (2015). Salmonellae interactions with host processes. Nat Rev Microbiol 13(4): 191-205.

8. Lelouard, H., Henri, S., De Bovis, B., Mugnier, B., Chollat-Namy, A., Malissen, B., Meresse, S. and Gorvel, J. P. (2010). Pathogenic bacteria and dead cells are internalized by a unique subset 
of Peyer's patch dendritic cells that express lysozyme. Gastroenterology 138(1): 173-184 e171173.

9. Liberali, P., Snijder, B. and Pelkmans, L. (2015). Single-cell and multivariate approaches in genetic perturbation screens. Nat Rev Genet 16(1): 18-32.

10. Lorkowski, M., Felipe-Lopez, A., Danzer, C. A., Hansmeier, N. and Hensel, M. (2014). Salmonella enterica invasion of polarized epithelial cells is a highly cooperative effort. Infect Immun 82(6): 2657-2667.

11. Misselwitz, B., Barrett, N., Kreibich, S., Vonaesch, P., Andritschke, D., Rout, S., Weidner, K., Sormaz, M., Songhet, P., Horvath, P., Chabria, M., Vogel, V., Spori, D. M., Jenny, P. and Hardt, W. D. (2012). Near surface swimming of Salmonella Typhimurium explains target-site selection and cooperative invasion. PLoS Pathog 8(7): e1002810.

12. Misselwitz, B., Kreibich, S. K., Rout, S., Stecher, B., Periaswamy, B. and Hardt, W. D. (2011). Salmonella enterica serovar Typhimurium binds to HeLa cells via Fim-mediated reversible adhesion and irreversible type three secretion system 1-mediated docking. Infect Immun 79(1): 330-341.

13. R Core Team (2013). R: A language and environment for statistical computing. R Foundation for Statistical Computing, Vienna, Austria.

14. Santos, A. J., Meinecke, M., Fessler, M. B., Holden, D. W. and Boucrot, E. (2013). Preferential invasion of mitotic cells by Salmonella reveals that cell surface cholesterol is maximal during metaphase. J Cell Sci 126(Pt 14): 2990-2996.

15. Snijder, B., Sacher, R., Ramo, P., Damm, E. M., Liberali, P. and Pelkmans, L. (2009). Population context determines cell-to-cell variability in endocytosis and virus infection. Nature 461(7263): 520-523.

16. Stecher, B., Hapfelmeier, S., Muller, C., Kremer, M., Stallmach, T. and Hardt, W. D. (2004). Flagella and chemotaxis are required for efficient induction of Salmonella enterica serovar Typhimurium colitis in streptomycin-pretreated mice. Infect Immun 72(7): 4138-4150.

17. Vonaesch, P., Cardini, S., Sellin, M. E., Goud, B., Hardt, W. D. and Schauer, K. (2013). Quantitative insights into actin rearrangements and bacterial target site selection from Salmonella Typhimurium infection of micropatterned cells. Cell Microbiol 15(11): 1851-1865.

18. Voznica, J., Gardella, C., Belotserkovsky, I., Dufour, A., Enninga, J. and Stevenin, V. (2018). Identifying parameters of host cell vulnerability during Salmonella infection by quantitative image analysis and modeling. Infect Immun 86(1): e00644-17.

19. Watson, K. G. and Holden, D. W. (2010). Dynamics of growth and dissemination of Salmonella in vivo. Cell Microbiol 12(10): 1389-1397.

20. Wickham, H. (2011). The split-apply-combine strategy for data analysis. J Stat Softw 40(1): 129. 